\title{
Revisión sistemática de literatura sobre comportamiento político y juventud en Latinoamérica y Costa Rica desde 1990 hasta 2016
}

Recibido: 16 de marzo 2017 Revisado: 4 de mayo 2017 Aprobado: 9 de junio 2017

Roy González Sancho Costarricense. Licenciado en Psicología y Máster en Estudios Latinoamericanos con Énfasis en Cultura y Desarrollo de la Universidad Nacional de Costa Rica. Investigador del Programa Agenda Joven de la Universidad Estatal a Distancia (UNED) de Costa

Rica. Miembro de la Asociación de Estudios Latinoamericanos (LASA).

Correo electrónico: rgonzalez@uned.ac.cr

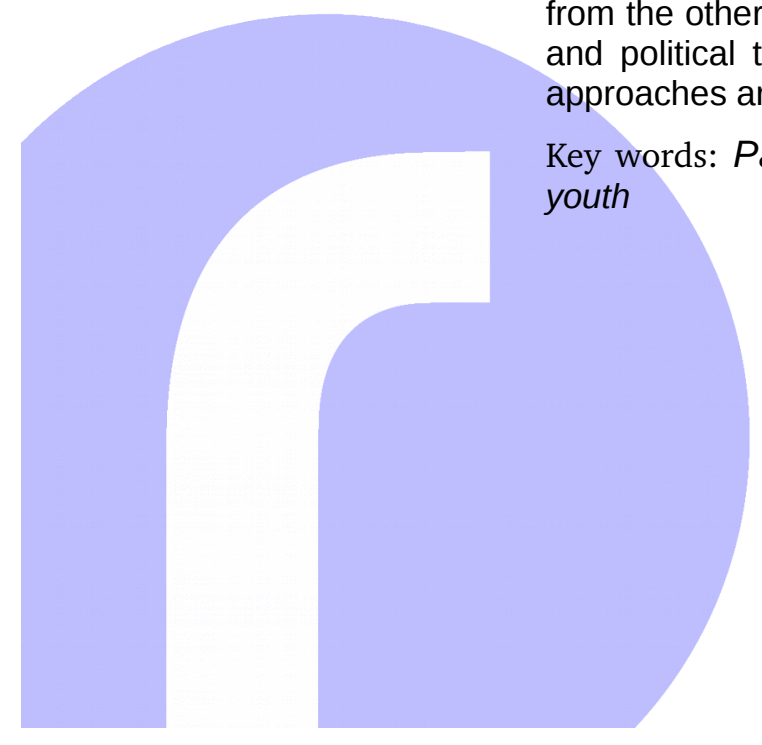

http://investiga.uned.ac.cr/rupturas/ (c) (1) (2) youth
Resumen: Este artículo presenta la sistematización de las investigaciones relacionadas con el comportamiento político-electoral en Costa Rica y Latinoamérica (inclusive algunos casos de España). Se enfatiza en el tratamiento y las ausencias del tema de juventud en este ámbito. Con un enfoque cualitativo y mediante la metodología conocida como revisión sistemática de literatura, se seleccionaron 124 artículos científicos de revistas indexadas en Redalyc.org y Kimuk.conare.ac.cr principalmente, estos fueron analizados con el programa informático AtlasTi7. Se encontró que el interés académico se enfoca en la participación política al margen de los demás temas. Se concluye que la credibilidad y la confianza políticas tienden a confundirse en su tratamiento, mientras que los abordajes de juventud tienden a ser menos en relación con el grueso de la investigación sobre el comportamiento político.

Palabras clave: Participación; Inclusión política; Confianza Política; Credibilidad; juventud

\section{A Systematic Literature Review on Political Behaivior and Youth in Latinamerica and Costa Rica from 1990 until 2016}

Abstract: This article presents a systematization of research related to political-electoral behavior in Costa Rica, and Latin America (including some researches from Spain). In addition a focused on treatment and absenses of youth in this topic. Thus, through a qualitative approach and by the methodology known as a systematic review of the literature, 124 scientific articles were selected from journals indexed mainly in Redalyc.org and Kimuk.conare.ac.cr, which were analyzed with Atlas.ti 7 Software. As a result, it was found that academic interest is focused on political participation apart from the other areas. In the conclusions, it was noticed that political credibility and political trust tend to be confused in their treatment. Meanwhile youth approaches are few in political behavior researches.

Key words: Participation; political inclusion; political trust; political credibility; 
1. Se ha agregado España debido a que el repositorio virtual Redalyc.org es una red que indexa revistas científicas de América Latina, el Caribe, Portugal y España. Al mismo tiempo, debido a la cantidad considerable de investigaciones españolas halladas en la revisión de literatura, se consideró oportuno incluirlas con el objeto de ampliar la discusión del tema de interés, sin perde de vista las salvedades del caso.

\section{Introducción}

El presente artículo tiene como objetivo principal analizar el abordaje en investigación académica y científica sobre el comportamiento político-electoral en Costa Rica y Latinoamérica, a partir de los siguientes temas: participación, inclusión, credibilidad política y confianza. Asimismo, se enfatiza en el tratamiento de las juventudes en estos ámbitos.

El estudio se desprende del trabajo de investigación realizado en el marco del Observatorio Político Electoral Juvenil (OPEJ) del Programa Agenda Joven de la UNED, en diferentes procesos electorales desde el año 2010.

De esta forma, se presenta una sistematización y un análisis de los trabajos de investigación realizados en Costa Rica, América Latina y algunas publicaciones de España, ${ }^{1}$ mediante una Revisión Sistemática de literatura que incluyó la consulta de los repositorios virtuales de redalyc.org y kimuk.conare.ac.cr.

El artículo, además de esta introducción, se estructura en cuatro apartados principales: aspectos teóricos, aspectos metodológicos, estrategia de análisis, análisis de las publicaciones encontradas y conclusiones.

Así, en los aspectos teóricos, se introducen brevemente algunas consideraciones sobre participación e inclusión política, credibilidad y confianza política y juventud. Mientras tanto, en el apartado metodológico se presenta el procedimiento y las herramientas empleadas para este artículo. En lo que respecta a los resultados del análisis, este se subdivide en cuatro partes. Se inicia con datos generales sobre todas las investigaciones seleccionadas, seguidamente por tres secciones temáticas sobre participación política, inclusión política y credibilidad y confianza política.

Estos segmentos temáticos presentan en cada caso una exposición de los resultados en América Latina por un lado, así como el análisis de las producciones de Costa Rica por el otro.

Finalmente, se ofrecen las conclusiones del proceso de análisis de los artículos estudiados, según los niveles básico y conceptual realizados con el programa Atlas.ti 7.

\section{Aspectos teóricos}

A continuación, se realiza una exposición abreviada de los lineamientos teóricos que guiaron el proceso de búsqueda, sistematización y análisis de los artículos científicos encontrados para la realización de esta primera fase del OPEJ 2016. 


\section{Comportamiento político}

De acuerdo con Anduiza y Bosch (2004), un objetivo fundamental en la existencia de un sistema democrático es asegurar o facilitar (cuando menos) el nexo entre las preferencias de los ciudadanos y los procesos de toma de decisiones. En este sentido, el estudio de los actores implicados y su comportamiento es trascendente para la comprensión de la vida política de una sociedad.

De esta manera y continuando con los aportes de Anduiza Perea y Bosch Gardella (2004), el comportamiento político puede ser definido como las formas o las variaciones en las cuales la ciudadanía se dirige o actúa en sus relaciones con el sistema político o con sus instancias representativas.

\section{Participación e inclusión política}

Precisamente, uno de los temas más importantes, a la hora de considerar el análisis del comportamiento político, es la participación de las personas implicadas en los procesos y las circunstancias inherentes a todo sistema político.

Al considerar esto, y dada la complejidad en las dinámicas que se pueden encontrar en el campo y los resultados de las investigaciones consultadas, la definición tomada en cuenta debía cumplir como requisito inicial abarcar varias de las dimensiones que la actividad política de las personas presenta. Por ello, aunque Anduiza Perea y Bosch Gardella (2004) toman en cuenta diversos elementos, se seleccionó la postura brindada por Molina y Pérez $(2000,995)$, para quienes la participación política puede ser entendida como:

... las acciones colectivas e individuales, legales o ilegales, de apoyo o de presión, mediante las cuales una o varias personas intentan incidir en las decisiones acerca del tipo de gobierno que debe regir una sociedad, en la manera como se dirige el Estado en dicho país, o en decisiones específicas del gobierno que afectan a una comunidad o a sus miembros individuales.

Lo anterior implica que al hablar de participación política, como uno de los rasgos distintivos del comportamiento político, no se puede delimitar a los espacios formales e institucionales pues los ejercicios de acciones o manifestaciones individuales y colectivas no pertenecen ni suceden de forma exclusiva en las plataformas formales. Dicho de otra forma, las relaciones sociales de consenso y conflicto no se agotan en estos escenarios.

No obstante, la participación política, como proceso formal y no formal, exige ciertas condiciones en pro de que las personas que componen la sociedad puedan involucrarse o manifestar sus inconformidades. En este sentido, Monsiváis Carrillo (2013) ha considerado que un régimen democrático debe 
2. Quien hace referencia de la inclusión política de las mujeres en esta elaboración conceptual. contar con las condiciones que posibiliten y garanticen oportunidades equitativas para tomar partido en los asuntos públicos, de forma inclusiva e imparcial.

Lo anterior quiere decir que si bien los ámbitos de acción política pueden originarse dentro del marco institucional (formal) o fuera de esta (no formal), deben existir ciertas garantías que aseguren una canalización de las preocupaciones o intereses de las personas.

Dichos aspectos hacen referencia a uno de los componentes esenciales que dentro de la noción de participación política aquí es considerada; es decir, la inclusión política la cual, siguiendo a Soto-Calderón (2003) y Sarabia-Ríos $(2014)^{2}$ corresponde a una interacción que tiene su inicio y su fundamento en el respeto por las diferencias, sin mediar ningún tipo de discriminación, que puede ser entendida como una ampliación de los derechos políticos y sociales de la ciudadanía para participar en equidad e igualdad de oportunidades en la dirección de los asuntos públicos y en el acceso a los puestos de la función política.

Esta consideración es clave a la hora de estudiar el comportamiento político, pues no solo se trata de entender teóricamente que la participación política enmarca las formas de accionar dentro o fuera de los canales institucionales provistos para estos efectos, sino que también existe una fundamentación en la cual las reacciones o peticiones populares encuentran los resguardos necesarios para su puesta en escena.

\section{Confianza política y credibilidad política}

\section{Confianza política}

Con lo expuesto anteriormente se entiende que el marco de análisis del comportamiento político es vasto e incluye tanto las dinámicas expresadas en las estructuras formales como aquellas que necesariamente no pasan por estas esferas.

Anduiza Perea y Bosch-Gardella (2004) han acotado que la participación política no es actividad homogénea que se extienda entre toda la ciudadanía, sino que mientras una parte de esta es muy activa, la otra mantiene una relación de distancia con la política (formal). Por lo tanto, la reflexión y el estudio en relación con las características de quienes participan y quienes no sea una de las cuestiones centrales del comportamiento político.

A partir de ello, puede notarse que hablar de comportamiento político también implica hacer referencia a algunos de los resultados o consecuencias que tiene la participación política. Entonces, mencionar aspectos como la confianza que las personas poseen en sus instituciones, o la credibilidad que como resultado de su trabajo, generan las instituciones del sistema político para ganarse la confianza de la ciudadanía, no son extraños en la discusión.

Los esbozos de la primera (confianza política) se pueden iniciar con los aportes de Gordon (2005), para quien la confianza puede ser identificada como 
un constructo o idea utilizado para describir la forma en la que las personas reducen la "incertidumbre" respecto de la conducta o el proceder de los otros, que se relaciona con el sentimiento de familiaridad, con los significados, prácticas sociales compartidas, etc., desarrollándose mediante un proceso de prácticas repetidas.

Estas últimas aseveraciones permiten vislumbrar que la acepción de confianza tratada en este particular no pretende ubicarla en la esfera de lo individual exclusivamente, sino que tiene por objeto demarcar su base para su explanación en el espacio de las dinámicas de la práctica política, es decir como un constructo que explique la confianza y el proceder que las personas tienen en las instituciones del sistema político.

En este aspecto son precisamente José Montero, Sonja Zmerli, y Ken Newton (2008), quienes consideran que se puede hablar de una confianza política, la cual se caracteriza por ser esa confianza perteneciente a la esfera pública y política, construida a partir de fuentes secundarias (como instancias del sistema político) y que se deposita no en personas concretas, sino en las instituciones formales, es decir, se refiere a las valoraciones de las instituciones centrales del sistema político realizadas por parte de las y los ciudadanos.

De manera que discutir sobre este tema es vital para denotar el tinte que podrían tener las relaciones que entabla la ciudadanía con los demás actores del sistema político. Al contemplar este punto, cobra importancia la explicación que realizan los autores antes mencionados sobre este mismo concepto:

...la confianza política en una institución conlleva la

creencia de que ésta no actuará de una forma arbitraria o discriminatoria que resulte dañina para nuestros intereses o los del país, sino que nos tratará, a nosotros y a los demás ciudadanos, de una forma igualitaria, justa y correcta

(Montero, Zmerli y Newton, 2008. 21).

Como puede verse el recurso de confiar en el sistema político, o bien en sus instancias, es utilizada para reducir la incertidumbre respecto del accionar de las instituciones políticas para y con la ciudadanía, de manera que la expectativa de recibir un daño o resultado desfavorable como resultado de una decisión o proceso político en particular sería menor, que si este elemento no existiese.

De esta forma, la confianza que un gobierno o sus instituciones puedan generar en sus ciudadanos puede ser clave para su desempeño y legitimidad, porque de una u otra manera la confianza política podría ser considerada un aspecto esencial en el respaldo que la ciudadanía otorga a un régimen o sistema político determinado. 


\section{Credibilidad política}

El tema tratado anteriormente, introduce un aspecto importante por considerar dentro del aspecto del soporte o apoyo que un sistema político pueda poseer, y que deriva en la consideración de las acciones que se realizan por parte de las instancias que lo integran para ganarse la confianza de sus ciudadanos o generarla.

Se está ante la parte complementaria (conceptualmente hablando) de la confianza que cada ciudadano tiene en las instituciones políticas; es decir, la credibilidad política que las instancias logran construir.

Una primera aproximación que merece ser tomada en cuenta es la realizada por Julio Amador-Bach (1995), quien ha señalado que la credibilidad es el acto por el cual una persona confía o considera que un discurso es verdadero. Dicha veracidad ocurre una vez que la persona ha comparado, revisado o contrapuesto el contenido del discurso y ha logrado relacionarlo con el conjunto de supuestos que componen el acervo colectivo que comporta o acredita como cierto un enunciado.

Todo lo anterior, sin ánimos de reducir la noción o las implicaciones de este concepto, que un mensaje, una institución, un líder o un partido político, tienen credibilidad en la medida que sus contenidos, acciones, manifestaciones o decisiones guardan una profunda relación con los repertorios de validez, aceptabilidad y veracidad que se encuentran socialmente establecidos. Cualquier contraste u oposición a dichos repertorios, implica una pérdida de esta cualidad.

La credibilidad política, propiamente dicha, no sería una calidad que una instancia adquiere solamente por seguir dicho dominio de lo social, sino que se aproximaría más a un resultado de procesos que han manifestado ser meritorios de confianza ante la opinión pública o especializada. Siguiendo los planteamientos de Zamitiz (1998), la credibilidad política en un sistema o instancia política se adquiere cuando se han logrado conseguir y mantener en el tiempo opiniones o valoraciones a favor de sí, que le acreditan como confiable.

De acuerdo con Marín y Rojas-López (2006), lo anterior se produce cuando las diferentes instancias integrantes de una institución han realizado un trabajo o puesto en marcha una serie de procedimientos de gestión y liderazgos, que contribuyen a la generación de una imagen pública confiable y la construcción de una reputación en distintos ámbitos de la sociedad, así también como la exposición de posturas conjuntas coherentes por parte de sus representantes que no generen malos entendidos o errores en la comunicación.

Por último, puede entenderse en el caso de este artículo que cuando se hace referencia a la credibilidad política se está considerando como el resultado del trabajo que una institución o instancia política ha realizado para ganarse la confianza de las personas y la posibilidad de ser considerado como veraz. 


\section{Juventud y adultocentrismo}

La comprensión del tema y el término juventud se dispersa en un gran número de posturas teóricas y posicionamientos políticos. Estos aspectos, así dispuestos, dificultan el desarrollo de una visión acabada de la cuestión; sin embargo, invitan en su lugar a hablar de enfoques sobre juventud.

En el caso de este artículo se ha decidido trabajar el tema empezando por su definición más genérica en la legislación nacional. Algunos aportes que describen, en buena medida, ciertas condiciones de vida, que afrontan las personas, que se encuentran en los linderos de lo que contemporáneamente se entiende por juventud.

Como forma de un primer acercamiento al tema, puede citarse el caso de la delimitación que aporta la Ley General de la Persona Joven (Ley N. ${ }^{\circ}$ 8261) para el caso de Costa Rica, en la que las personas jóvenes se definen como aquellas que se encuentran entre los 12 y los 35 años.

Si bien, esto representa tan solo un acercamiento instrumental, en la misma formulación de la ley se han considerado a las personas jóvenes como un actores sociales y políticos, como un grupo social con particularidades y necesidades específicas que al amparo de esta ley debe "garantizárseles" mediante la ejecución de políticas públicas, el desarrollo de investigaciones y la apertura de espacios de participación política.

Precisamente, este elemento permite la introducción de otros también pertinentes al tema de juventud, el primero de ellos le concierne a Souto Kristín $(2007,171)$, quien ha planteado que la juventud: “....se puede definir como el periodo de la vida de una persona en el que la sociedad deja de verle como un niño, pero no le da un estatus y funciones completos de adulto".

Lo anterior permite vislumbrar, en buena medida, que una posible definición de la juventud se acerca más a identificarla como un grupo social, en lugar de centrarse únicamente en el criterio de la edad como eje central de su delimitación. Asimismo, Souto Kristín (2007) lo ha advertido al recordar que, como todo grupo de una sociedad, la juventud nunca ha conformado un todo homogéneo, sino que han expresado en su esencia las divisiones sociales, económicas, culturales y políticas presentes en la sociedad donde se desenvuelven.

De esta manera, además de la diversidad intrínseca a este grupo social, ha de sumársele el limbo social y político que viven, en el que prima la paradoja de ser sujetos de derecho, pero con posibilidades limitadas para acceder y ejercer sus facultades como tales. Lo anterior ocurre paralelamente a la existencia de cuerpos legales cuyas disposiciones no han logrado resolver esta situación ${ }^{3}$.

3. Para mayor detalle para el caso costarricense, consulte: González Sancho, Roy \& Evita, Henríquez Cáceres (2016).

Participación juvenil en espacios formales de deliberación política: entre

No obstante, la presencia de estas limitaciones e impedimentos no es gratuita ni mucho menos extraña para la organización de las estructuras que sostienen o fundamentan las relaciones sociales, al menos en el caso Occidental. 
Dichos linderos de acción y disposiciones en las relaciones sociales, se denominan adultocentrismo, el cual siguiendo a Zúñiga Núñez $(2003,6)$, puede ser explicado de la siguiente manera:

Vamos a entender el adultocentrismo en términos foucaulteanos como una disciplina, creada en el contexto de las relaciones sociales de occidente, donde las actividades teleológicas, los medios de comunicación y las relaciones de poder; están más o menos relacionados de manera que, se caracterizan por ubicar "lo adulto" de forma esencial (madurez, responsabilidad, integración al mercado de consumo, motor de la producción, etc.) como punto de referencia del "deber ser" social. Lo cual deja en posibilidad a los grupos o personas que se denominen como "adultos" de gobernar poblaciones de edades diferentes (niñez, juventud, vejez).

Se infiere que al hablar de adultocentrismo, se alude a una lógica de organización, la cual funciona a partir de un criterio discriminante compuesto por la edad, desde la cual se configuran las posibilidades de intercambios entre las diferentes poblaciones. Dicho de otro modo, las relaciones entre el "ser central" (adulto) alrededor del cual se definen las dinámicas sociales, económicas y políticas, con el resto de los conjuntos de sujetos que participan (por así decirlo) en el universo de interacciones e intercambios posibles o permitidos.

Podría decirse que se trata de una forma de organización del ejercicio del poder que cruza transversalmente todas, o por lo menos la gran parte, de las áreas del quehacer humano. Duarte (2012) ha planteado un sistema de dominación que ha encontrado su fortalecimiento en la realización de las prácticas de organización social propias del capitalismo. Ello genera un ámbito fértil para su reproducción o reelaboración tanto en lo político como en lo económico. Al mismo tiempo, el autor reconoce que el adultocentrismo, también, se ha desplegado con mecanismos de reproducción en lo cultural y lo simbólico.

De esta manera, se puede observar que tanto juventud como adultocentrismo son entidades de socialización que conviven en las sociedades actuales, con la salvedad de que la segunda se impone sobre la primera y permea en sus estructuras de interacción, cuya repercusión puede observarse en las personas que constituyen y reproducen las formas de accionar, propias de esta lógica de organización del entorno humano, en su relación social con sus semejantes y aquellos sujetos considerados como los inferiores. 


\section{Aspectos metodológicos y estrategia de análisis}

El trabajo para este artículo se ha realizado desde un enfoque cualitativo, porque no se ha realizado ningún proceso de cuantificación estadística y el material analizado es principalmente documental. Este rasgo es reconocido por Flick (2015), como un elemento clave de la investigación cualitativa, en su pretensión de conocer un fenómeno social determinado desde el interior de sus propias dinámicas, las cuales, en este caso, han sido la producción científica alrededor del comportamiento político, que se ha publicado tanto en Costa Rica como en América Latina con énfasis en los vacíos y el tratamiento de las personas jóvenes en los ámbitos seleccionados.

Al mismo tiempo, el alcance de la investigación realizada para este artículo ha sido descriptivo, pues como mencionan Lafuente y Marín (2008, 9-10):

La investigación descriptiva la llevamos a cabo cuando queremos mostrar las características de un grupo, de un fenómeno o de un sector, a través de la observación y medición de sus elementos. La información que nos proporciona un análisis descriptivo, además de ser un fin en sí mismo, la podemos utilizar como base de partida para el desarrollo de una investigación más específica.

La revisión documental aquí detallada ha tenido como principal propósito, recoger un panorama pormenorizado de varios componentes claves seleccionados para entender cómo se ha desarrollado la investigación científico-social con respecto al comportamiento político, en los contextos antes mencionados. ${ }^{4}$ Además, este recorrido analítico, por los diferentes artículos revisados, ha servido como punto inicial para el desarrollo de las subsecuentes etapas del proceso de investigación del OPEJ para el año 2016.

Ahora bien, el método utilizado para la realización del trabajo que compone este artículo fue la revisión sistemática de literatura o RS, la cual de acuerdo con Manterola, Astudillo, Arias y Claros $(2013,149)$ puede ser definida como "...un artículo de síntesis de la evidencia disponible, en el que se realiza una revisión de aspectos cuantitativos y cualitativos de estudios primarios, con el objetivo de resumir la información existente respecto de un tema en particular".

Este tipo de estudio es relevante para el desarrollo de sucesivos estudios como el presente, pues tomando en consideración lo señalado Beltrán (2005, 65), las revisiones sistemáticas de literatura, además de lograr un recuento y análisis profundo del estado investigación básica en un tema específico, sobrepasa las limitaciones de las revisiones narrativas ${ }^{5}$, al ser aplicados en su desarrollo estándares rigurosos de procesamiento, estudio e interpretación a sus unidades de análisis (investigaciones previas), al mejor estilo de una investigación primaria.

5. En palabras del autor, revisiones de antecedentes o investigaciones previas en las que no había mayor detalle en la recolección de los datos de las fuentes primarias (investigaciones). 
6. La unidad hermenéutica es el archivo principal a partir del cual el programa Atlas.ti asigna un número de identificación a cada archivo analizado y se pueden llevar a cabo todas las acciones y las tareas que permite el programa informático de análisis cualitativo.
En cuanto a la estrategia de sistematización y análisis de las unidades estudiadas (artículos científicos), como primer paso, se seleccionaron las plataformas electrónicas de la Red de Revistas Científicas de América Latina y el Caribe, España y Portugal: Redalyc.org y en el Repositorio Nacional de Costa Rica: kimuk.conare.ac.cr. La primera es el portal con mayor cantidad de artículos científicos en sus registros provenientes de América Latina (dando resultados más amplios que Scielo.org y ebscohost.com). En el caso de kimuk.conare.ac.cr., su selección se basó por ser el repositorio electrónico de investigaciones académicas nacionales más grande y completo a la fecha de realización de este artículo.

Los descriptores de búsqueda utilizados para la selección de los artículos científicos fueron: 1. Participación política y juventud, 2. Inclusión política y juventud, 3. Credibilidad política y juventud, y 4. Confianza política y juventud. De esta forma, para la muestra inicial del trabajo, se encontraron más de 300 unidades de análisis en la primera fase de revisión.

Como segundo paso se procedió a realizar una revisión preliminar para descartar aquellos escritos que no aportaban información relevante sobre el estado de la investigación del comportamiento político, por lo que se redujo la cantidad de artículos a 124 directamente relacionados con el tema de interés. Algunos de estos incluían, dentro de sus muestras poblacionales, a personas jóvenes.

Para el análisis a fondo de los artículos seleccionados, se utilizó la aplicación informática denominada Atlas.ti 7, la cual de acuerdo con Friese (2015) es una herramienta para el análisis cualitativo de datos textuales, gráficos, de audio y video sin estructurar de gran calado y que no pueden ser analizados mediante métodos estadístico-formales.

Asimismo, se realizó un análisis en dos niveles, los cuales siguen los señalamientos de Friese (2015). Se trata de grados de análisis y profundidad que van desde la organización de los códigos y las citas tomadas de los textos primarios, hasta la interpretación de las relaciones e interpretaciones encontradas a partir de la primera etapa.

De esta manera, el primer paso de análisis correspondió con una identificación de datos presentes en las unidades de análisis (análisis básico de datos) donde se identifican los códigos presentes en los textos analizados, así como la demarcación de citas textuales relevantes vinculadas a dichos códigos. Mientras tanto, en la segunda etapa del análisis, se realizó una serie de pasos más elaborado detallando las relaciones entre los datos identificados (relaciones a nivel conceptual).

En el nivel de análisis básico de datos, tiene lugar la conformación de la unidad hermenéutica ${ }^{6}$, así como la codificación. En detalle, este proceso fue llevado a cabo identificando en cada artículo para su clasificación y posterior análisis los siguientes cuerpos de códigos: a) uso conceptual de cada una de las categorías de análisis (es decir: participación, inclusión, confianza y credi- 
bilidad), b) enfoque metodológico utilizado, c) alcance de la investigación, d) los instrumentos de recolección de información (método), e) población participante, f) país de procedencia, g) resultados y h) conclusiones.

Cada uno de los anteriores nombres de listados corresponde a una familia en la que se agrupan varios códigos, los cuales se asignaban en cada unidad estudiada. Adicionalmente, se seleccionaron citas y se anotaron comentarios analíticos sobre las conclusiones o los resultados presentes en las unidades de análisis que fueron luego de gran importancia.

Una vez hecho esto, se realizó un análisis a nivel conceptual, en el que se enfatizó la búsqueda y la visualización de las relaciones existentes entre las diferentes familias de códigos. Se dio lugar a una interpretación y se rescataron algunas de las afirmaciones más importantes presentes en los artículos estudiados y los comentarios analíticos anotados, en varias ocasiones, en la fase anterior.

Como parte de las prestaciones que permite la aplicación Atlas.ti 7, se obtuvieron las coocurrencias entre las diferentes familias de códigos analizadas en los artículos. Esta prestación del programa es importante debido a que, como ha mencionado Friese (2015), la coocurrencia es una herramienta que mediante una visualización de "árbol" o tabla cruzada permite visualizar los "cruces" o superposiciones de códigos en las citas que se seleccionan en un texto, de manera que se pueden encontrar las coincidencias entre los diferentes conceptos utilizados para la codificación. Las coocurrencias obtenidas fueron imprescindibles para el análisis que, aquí, se presenta como un resultado del proceso de investigación.

De esta forma, la revisión sistemática de literatura realizada se desarrolló siguiendo un proceso de escrutinio y revisión detallado, en el que se pensó en todo momento lograr un panorama lo más completo y confiable sobre el tratamiento del comportamiento político y la forma en cómo se abordaban a las personas jóvenes en los artículos estudiados.

\section{Análisis de las publicaciones encontradas}

A continuación, se desarrolla un análisis de las investigaciones. Se presenta, inicialmente, un análisis general de todas las publicaciones seleccionadas, mientras que en el caso de cada subcategoría, primero, se detallan los estudios recolectados de provenientes de América Latina y luego aquellas correspondientes a Costa Rica.

Se han citado algunas de las acotaciones más representativas de las tendencias encontradas a lo largo de la revisión de la literatura realizada para este artículo, a modo de ejemplo y respaldo del análisis presentado. 
7. En lo sucesivo, las cantidades de ocurrencias de los conceptos o categorías reportados se detallan con números, entre paréntesis, al lado del concepto del que se trate.
Primer acercamiento, datos generales al panorama en investigación científica sobre el comportamiento político

La búsqueda de los artículos científicos sobre el presente tema se realzó al priorizar a América Latina y Costa Rica. Sin embargo, se agregaron algunos estudios de España que fueron considerados importantes para su incorporación en este artículo. Como resultado de este proceso, se seleccionó, finalmente, un total de 124 publicaciones, de las cuales aproximadamente 60 se agruparon en la categoría de Participación Política, 19 fueron exclusivamente concernientes a la categoría de Inclusión Política (por lo que se requirió separarlas), 26 en Confianza y Credibilidad Política, y 19 tocaban temas relacionados con personas jóvenes y las anteriores categorías juntas. ${ }^{7}$

En cuanto a los países de proveniencia, casi la mitad de todas las publicaciones tomadas en consideración son costarricenses (58), mientras que en términos de volumen de hallazgos se destacaron México (15), España (14), Chile (14), Colombia (12) y Argentina (9).

Sobre aspectos metodológicos, pudo verse que los abordajes de las categorías y subcategorías de análisis han sido principalmente desde un enfoque cualitativo de investigación (83) seguido del cuantitativo (33) y, por último, el mixto (8). En lo que respecta al alcance de los estudios analizados, la mayoría de estos han sido descriptivos (62) seguidos de interpretativos (39), explicativos (14) y correlacionales (13).

De los métodos más habituales de llevar a cabo los estudios recolectados para este artículo por parte de las y los investigadores ha sido especialmente: el análisis bases de datos (41), el ensayo (38), la revisión de hechos históricos (36) y la encuesta (25).

La mayoría de los trabajos cualitativos han sido de alcance descriptivo e interpretativo, mientas que los cuantitativos han sido descriptivos, correlacionales y explicativos. En una gran parte de los casos, las poblaciones consideradas para las investigaciones o propuestas de análisis han sido personas mayores de edad; es decir, personas jóvenes y adultas, escasos estudios en los temas de consultados han sido específicamente de personas jóvenes o menores de 18 años de edad.

Cabe resaltar algunas relaciones de coocurrencia obtenidas con el Atlas.ti 7 que resultaron interesantes para el propósito de este artículo. El primer caso se presentó entre el grupo de conceptos de Participación política con los de Inclusión política (442 ocasiones) y los de Confianza y Credibilidad política (265 ocasiones). El segundo se trata del grupo de conceptos de Inclusión política con los conceptos de Confianza y Credibilidad (154 ocasiones).

\section{Participación política}

Partiendo del análisis realizado, se ha denotado que los trabajos sobre participación específicamente han sido investigaciones realizadas desde un enfoque cualitativo con alcances descriptivos e interpretativos, principalmente. 
Una cantidad importante de los mismos ha concentrado su atención en la discusión sobre asuntos o preocupaciones relacionadas con el derecho a la participación y su cumplimiento. Se tiene como sustrato o medio de revisión del tema bases de datos o de eventos históricos específicos. Otros puntos de interés emergidos durante la revisión general sobre este tema, fueron los espacios de participación de diferentes poblaciones, el cumplimiento del derecho de reunión y las percepciones que tienen diferentes actores sobre su derecho de participación en las distintas esferas de acción del Estado y la sociedad.

\section{Participación política en América Latina y España}

En un segmento diferente del análisis, luego de estudiar las publicaciones sobre participación política, se ha podido evidenciar que dicha temática ha sido abordada desde una amplia variedad de disciplinas de las ciencias sociales, entre estas la ciencia política especialmente, también la historia y la sociología. De la misma forma, se ha podido constatar que cuando los autores y las autoras discuten e investigan sobre participación, lo hacen desde una diversidad teórica que trasciende la politología como tal. Se reciben aportes desde disciplinas como la historia, la sociología o la psicología social, por ejemplo.

Un aspecto necesario por destacar, que ha surgido a partir de la lectura de las discusiones y análisis de varias investigaciones, especialmente en los casos específicos de España y Argentina, está relacionado con la incapacidad que han tenido las instancias municipales estudiadas de capitalizar la participación ciudadana de las personas en sus localidades, a pesar del desarrollo de programas dedicados a este propósito (Bonet i Martí, 2012; Pastor Seller, 2011; Ramírez Viveros, 2012; González Salcedo, 2011; Morales-Diez, 2001; Ballester y Blanco, 2011; Carmona y Martínez, 2013).

Asimismo, aparejado con este panorama, se ha puesto en evidencia que estas iniciativas de participación desarrolladas o mediadas institucionalmente (en municipalidades o ayuntamientos) han sido deficientes en sus procesos de formación en ciudadanía, de manera que se tiende a pensar que a la falta de programas de formación y participación ciudadana adecuados para las comunidades, estas no terminan por enterarse de las posibilidades de participación o involucramiento que tienen en los espacios formales.

Todo lo anterior podría estar contribuyendo, al mismo tiempo, de acuerdo con las autores y los autores, con el sentimiento que las personas tienen respecto de la lejanía o desvinculación que se considera que la política tiene para y con ellas como ciudadanía. (Fouce, 2008; Ruiloba Núñez, 2014; Martínez-Labrín, Blanco-Hadi, Farías-Olavarría, Orellana-Fonseca, Pérez-Díaz, Cárcamo-Vásquez y Bivort-Urrutia, 2015; Canto Chac, 2008; Morales-Diez, 2001; Pac-Salas y Minguijón, 2011; Botero Gómez, Torres Hincapié y Alvarado, 2008; Holzner, 2007).

Tanto las publicaciones de los casos latinoamericanos, como las españolas, parecen evidenciar que parte de las deficiencias observadas como resultados de los programas enfocados en la participación política ciudadana, se deben a la escasez de recursos económicos para su desarrollo o sustentabilidad 
temporal, así como un adecuado marco legal o reglamentación que permita realizar adecuadamente los programas.

La participación aparece en el caso latinoamericano, principalmente, bajo su consideración electoral. Eso sí, en varios de los artículos, se advierte que este tema debe ser comprendido, en la actualidad, desde un punto de vista más amplio que la emisión del voto, las campañas electorales o la representatividad política, debido primordialmente a su complejidad.

También, se perciben ciertos límites de la democracia representativa, puesto que las poblaciones jóvenes, que participan activamente, poseen niveles de criticidad con respecto a las posibilidades y los alcances reales de los mecanismos o los canales de formación y participación de los sistemas democráticos (Brussino, Sorribas y Rabbia, 2009; Torres-Hincapié y Botero-Gómez, 2008; Pataro, Lenzi y Avirro, 2008; Holzner, 2007; Casas, 2009; HatibovicDías y Sandoval Moya, 2010).

Otras publicaciones sí dejaron ver que es habitual que los Estados destinen muchos recursos financieros y humanos al campo electoral y la participación en este tipo de procesos. Como efecto asociado, las campañas electorales gozan de coberturas amplias, por parte de los medios de comunicación, del país de turno.

No obstante, resulta interesante que, con respecto a las instancias encargadas de velar y promover la participación de la ciudadanía, se ha tendido a ver que sus propuestas y proyectos no solo se ven mermados en recursos económicos y humanos, sino también, en muchos casos, sus ámbitos de acción conciben la participación política únicamente dentro del sistema político formal.

Mientras tanto, en otras referencias, se ha señalado que, en algunos casos, se adolece de normativas claras, lo cual acaba teniendo un efecto negativo y entorpeciendo (de acuerdo con algunas referencias) las iniciativas ciudadanas (Alejandre-Ramos y Escobar-Cruz, 2009; Ruíz Martínez, 2015; Somuano-Ventura, 2005; Carrasco-Azzini, 2010; Poggi y Salomón, 2015).

En este sentido, una acotación que ilustra estas tendencias puede ser la aportada por González Salcedo $(2011,17)$, quien ha descrito la situación de Madrid y Helsinki entrevistando representantes municipales de ambas ciudades. Al respecto, el autor señaló que:

Las deficiencias presupuestarias también son señaladas en ambas ciudades como importantes obstáculos para la participación. En Helsinki no existe ningún presupuesto específico para las prácticas participativas, debiendo obtenerse recursos para la participación de otras partidas. En el caso de Madrid, las dificultades financieras son destacadas por todos los entrevistados... En tercer lugar, 
existen, en los dos casos, problemas con las normativas que guían, o dejan de guiar, los procesos participativos. En el caso de Madrid, los representantes del Partido Popular y los técnicos del Ayuntamiento han mostrado su preocupación por la falta de disciplina de los ciudadanos para adaptarse al reglamento de participación.

Al mismo tiempo, parece ser, al menos en la literatura revisada, que la participación en espacios de política formal o el involucramiento con ciertas causas políticas está relacionada con la adquisición o el goce de ciertas condiciones sociales, educativas y económicas, que promueve que las personas se integren.

Entre tanto, otras investigaciones refieren a que las personas de bajos recursos socioeconómicos, en muy pocas ocasiones, participan o se involucran procesos y espacios políticos formales, porque en su lugar estas personas tienden a orientarse a la resolución de actividades y necesidades individuales más apremiantes en sus contextos inmediatos.

Partiendo de lo anterior se entiende la dificultad de que grupos poblacionales como las personas jóvenes no participen o se vean alejados de los espacios de participación política formal (Sorribas y Garay Reyna, 2014; Ballester y Blanco, 2011; Boneti i Martí, 2012; Gillman, 2010; Martínez Labrín, Blanco Hadi, Farías Olavarría, Orellana Fonseca; Pérez Díaz; Cárcamo Vásquez y Bivort Urrutia, 2015; Holzner, 2007; González y Henríquez, 2014).

Además, la poca confianza y la corrupción que se perciben en los poderes de los diferentes sistemas políticos, así como en los partidos políticos, sus candidatos y representantes, aparece comúnmente ligado al deseo de las personas jóvenes y adultas casi en proporciones iguales de no participar en política formal, especialmente en aquellas que se afectan directamente por estas situaciones.

No obstante, a pesar de que se "da por un hecho" que las clases políticas y dirigentes políticos cometen actos de corrupción, se sigue manteniendo la creencia extendida de que el sistema político es necesario para la resolución de asuntos de interés público; o bien, para abrir espacios de participación para distintos sectores de la sociedad, por ejemplo, las personas jóvenes (Lozano Ardilla, 2008; Montalvo, 2008; Bustos Pizarro, 1997; Sánchez-Ramos, 2009; Tabares-Ochoa, 2013; Hatibovic-Días y Sandoval Moya, 2010).

Siguiendo con el caso específico de las publicaciones que atañe en sus poblaciones de estudio a personas jóvenes, se identificó que ellas, en general, confían en el sistema democrático y conciben la democracia como un sistema que junto con sus valores es funcional para la resolución de los problemas y las discusiones de relevancia colectiva. 
Sin embargo, parece generalizada la sensación de desconfianza hacia quienes ejecutan o se encargan de velar por la participación de la ciudadanía, casi sin importar si dichas personas en cargos políticos fuesen nombrados o electos mediante un proceso electoral nacional o local (Gillman, 2010; LópezSerrano y López Serrano 2009; Murga Frassinetti, 2009; Díaz-Gómez; Salamanca-Aragón, 2012).

En su publicación, Gilman (2010, 342-343), expone claramente este último punto de la siguiente manera:

Reconozco entre los sujetos jóvenes una separación significativa entre sus conceptos de democracia y política. Conciben la democracia como un régimen de valores, o como una configuración colectiva de individuos, pero no como un sistema político. Caracterizada por ideales como la libre expresión, la igualdad, la solidaridad, el respeto y el cuidado por los demás, la democracia se caracteriza como un campo de inclusión y equidad. En contraste con la democracia, la política es un campo de exclusión, caracterizado por valores que consideran específicamente antidemocráticos, sinónimo de desigualdad y corrupción, y que se materializa en una organización social dividida que fortalece un sistema de "differentiated citizenship".

De esta forma, logra verse que la contradicción percibida por las personas jóvenes, entre el ejercicio político y el sistema democrático, podría estar reflejando una de las tantas facetas de las barreras estructurales que esta población enfrenta: el adultocentrismo percibido en la gestión y manejo de la política formal.

A nivel de análisis de los temas discutidos, hubo aproximaciones al tema del género, específicamente en cuanto a la participación de la mujer en partidos políticos y puestos de elección popular. En estas publicaciones, se menciona que las mujeres tienden a estar relacionadas con espacios más organizativos a nivel de participación partidaria, en tanto que los hombres ocupan puestos de candidaturas elegibles o representativas de los partidos (Botero Gómez, Torres Hincapié y Alvarado, 2008).

Como punto de cierre para esta sección del análisis, y al apreciar de manera global los aportes de los diferentes autores, puede llegarse a denotar que las personas jóvenes parecen diferenciarse u oponerse en sus posturas y percepciones con respecto a los conceptos fundamentales de la participación 
política formal, la democracia o la política en general sostenidos por las poblaciones adultas.

Sin embargo, a partir de las distintas publicaciones revisadas, es arriesgado sostenerlo como una verdad absoluta, pues en su lugar las nociones sobre los problemas y las necesidades apremiantes en las diferentes sociedades parecen ser compartidas tanto por personas jóvenes como adultas.

\section{Participación política en Costa Rica}

En el caso costarricense, uno de los temas que más se ha trabajado en profundidad en las publicaciones revisadas ha sido la participación política de las mujeres. Varias investigaciones se han centrado en analizar el desarrollo de las pugnas que distintos movimientos políticos han tenido que llevar a cabo para conseguir una digna representación política para las mujeres a lo largo de todo el siglo anterior.

De esta forma, la variedad de los hechos estudiados van desde las luchas en las primeras décadas del siglo pasado por el sufragio femenino encabezado por el movimiento de las Sufragistas y las Mujeres del Partido Vanguardia Popular, así como su consecución como derecho en los años 1950; la incorporación de mujeres de sectores populares en distintos movimientos o agrupaciones a favor de los derechos políticos y humanos de las mujeres en los años 1980 (Alvarenga Venutolo, 2012; Romero, 1986; González Suárez, 2006; Mora, 2001; Piedra, 2001; y Carillo Padilla, 2012); hasta las luchas políticas por las cuotas de participación femenina en los partidos políticos, la incorporación en el campo político de movimientos de mujeres de sectores populares y la superación de la inequidad política (Sagot-Rodríguez, 2010; Angulo Brenes, 2010; Pérez, 2009; Ramírez Granados, 2010; Morales-Rojas, 2014; López, 2012; Rodríguez y Mora, 2011; Barrancos, 2013).

Un ejemplo de estos abordajes, lo ha llevado a cabo Sagot-Rodríguez (2010, 40). En su artículo, la investigadora analizó el tema de las cuotas de participación femenina de la siguiente manera:

Desde la anterior perspectiva, aunque la existencia de una normativa sobre cuotas aumenta la posibilidad de que las mujeres lleguen a puestos de elección popular, no hay garantía sobre el tipo de mujeres que llegará a ocupar esos puestos, ni sobre su agenda política. En el caso de Costa Rica, los principales partidos han elegido a mujeres altamente disciplinadas y fieles a la línea partidaria, con relaciones cercanas - casi subordinadas- con los hombres importantes de esos partidos y poco dispuestas a desafiar el statu quo. 
8. Comités Cantonales de la Persona Joven.el que se trate.
Esta anotación refleja, quizás, uno de los puntos más importantes en la lucha de las mujeres por el reconocimiento de sus derechos políticos desde el siglo XX hasta la actualidad. Al mismo tiempo, muestra el encuentro de ciertos paralelismos con las dinámicas observadas como limitaciones sufridas por las personas jóvenes que se involucran en procesos políticos formales; es decir, el acceso a ciertos puestos de elección popular o de toma de decisiones, pero bajo estándares de acción condicionados o restringidos en sus posibilidades de repercusión.

Un tema de interés, ampliamente desarrollado en varias publicaciones, fue el referendo del año 2007, evento en el cual a la luz de los conflictos sociales y políticas acaecidas, surgen las figuras de los Comités Patrióticos, los cuales han sido una de las instancias, quizás, más llamativas y que se erigieron en su tiempo como una alternativa de participación política para personas provenientes de varias posturas ideológicas distintos movimientos sociales y de todos los grupos de edad. Se concentró, principalmente, en aquellas personas que no estaban a favor con el Tratado de Libre Comercio entre Estados Unidos, Centroamérica y República Dominicana.

De acuerdo con las autores y los autores, dichas agrupaciones se conforman como resultado del malestar histórico acumulado desde décadas antes. Junto con esto, otras dinámicas de participación política como las acciones colectivas han sido estudiadas desde sus dinámicas de alcance local y nacional (Álvarez Rudín, 2011; Vindas Solano, 2014; Cortés Ramos, 2014; Vega, 1997; Rodríguez Arce y Ulloa Sáenz, 2012; Álvarez, 2011; Ramírez, 2011).

Sin embargo, a pesar de que en estas investigaciones no se ha mencionado el involucramiento de personas jóvenes en estas instancias y dinámicas de participación política, sí ha saltado a la vista que en estos eventos (acciones colectivas) y movimientos particulares (Comités Patrióticos) participaron personas de todos los grupos de edad.

Otro tema que cuenta con una vasta cantidad de estudios es el abstencionismo, junto con investigaciones relacionadas a explorar la concepción de democracia, entre otros (Araya-Alpízar, 2015; Jensen Pennington y Campos Ramírez, 1991; Abarca, 2014; Aguirre Ramírez 2000; Calderón, Sandoval, Alfaro, González, y Carrillo, 2013; Morales Ramírez, Castro Pérez y Bolaños Mora, 2015; Angulo, 2010).

Finalmente, en específico sobre personas jóvenes y su participación en espacios de toma de decisiones vinculantes, son pocas las referencias encontradas. No obstante, en este aspecto se destaca el trabajo de Franceschi Barraza y Chaves Zúñiga (2014) en relación a las dinámicas de participación política en algunos CCPJ's ${ }^{8}$ de la región occidente del Valle Central. En dicha investigación, se discuten las condiciones particulares de la participación política de las personas jóvenes que participan dichas instancias.

En este sentido, en dicha investigación, se detalló la situación de la siguiente manera: 
Si bien hay espacios estatales en los que se toma en cuenta a las personas jóvenes, se circunscribe generalmente a las áreas tradicionales de recreación, cultura y capacitación, promoviendo una participación en forma subordinada a las directrices de las autoridades locales adultas. En este caso, estamos ante un escenario en el que el gobierno nacional y municipal- responsables de la política de juventud- propician una participación restringida y controlada, distante de la realidad de los derechos de las juventudes.

Nos encontramos con una ilusión de participación de los jóvenes en los espacios abiertos por la Ley de la Persona Joven, ya que el discurso los incluye; no obstante, las prácticas políticas de participación en toma de decisiones, los limitan y excluyen como categoría social diversa y heterogénea (Franceschi Barraza y Chaves Zúñiga, 2014, 21-22).

Este pasaje introduce una serie de elementos que sustentan la apreciación anterior, al respecto de elementos en común encontrados sobre las barreras que enfrentaron en su momento. Según las publicaciones revisadas, las mujeres luchan por lograr espacios de participación y representación política dentro de las estructuras partidarias. A pesar de los avances en esta materia, las condiciones en las que dichos progresos han tenido lugar, limitan los alcances de las eventuales propuestas o los proyectos políticos que las personas jóvenes pueden plantear o ejecutar, de ser el caso.

\section{Inclusión política}

En aspectos generales para este apartado se repite el patrón anterior. Predominan estudios de enfoque mayormente cualitativos y de alcances descriptivos e interpretativos con la diferencia de que el foco de atención ha estado en elementos como participación ciudadana y el cumplimiento del principio de igualdad y no discriminación. Se tiende a la relevancia de estudios descriptivos sobre el derecho de expresión. Todo esto, a partir de la revisión de bases de datos, resultados de encuestas o censos nacionales. 


\section{Inclusión política en América Latina}

La inclusión política se encuentra mencionada o contemplada en varias de las investigaciones revisadas sobre participación política, pues al parecer para que esta última se desarrolle de manera óptima, se requiere la presencia de condiciones y garantías que avalen la inclusión de la ciudadanía de todas las edades en los procesos decisionales (Gutiérrez Briceño y Rodríguez Colmenares, 2012; Gillman, 2010; Massal, 2006; Vargas, 2003 y Calvo de Mora, 2011). De esta manera, es recurrente la alusión a la inclusión política de las actoras y los actores en los análisis del desarrollo de un proceso político o su evaluación.

Al mismo tiempo, otros estudios insisten en acotar que para una participación política efectiva debe garantizarse que la inclusión de los actores tomados en consideración se realice en términos reales y concretos, pues ello correspondería con un primer peldaño necesario para lograr la incorporación de aquellos sectores de la sociedad que no han sido incluidos anteriormente o que han sido históricamente relegados (Ramos Calderón, 2012; Oyarzún Chicuy, 2001; Ponce, 2014 y Calderón, 2011).

Mientras tanto, la inclusión política y la juventud, como temas centrales de análisis en las producciones académicas revisadas, parecen en sí una temática poco explorada por investigadores, lo cual resulta un poco inquietante si se tiene en cuenta que algunos autores han externado la necesidad de que, a nivel del quehacer político, es necesaria incorporación de las personas jóvenes como sujetos de derechos y actores políticos claves de las dinámicas y desarrollo de propuestas políticas, más allá de su papel habitual en tiempos de campaña electoral (Oyarzún Chicuy, 2001; Álvarez Torres y Monsiváis Carrillo, 2015; Ferreira, 2014; Rodríguez y Gutiérrez, 2012; Rueda, 2013).

La participación femenina aparece relacionada con el tratamiento del tema de inclusión efectiva en materia de partidos políticos y procesos electorales, especialmente cuando se hace referencia a las luchas por la definición de las cuotas de participación e inclusión de mujeres en las fórmulas electorales que presentan los partidos políticos para dichos periodos (Ferreira, 2014; Sarabia, 2014; Barry, 2006; Godoy Ramos, 2013).

Al tener claro un poco el panorama en este tema, llama la atención que tanto mujeres como personas jóvenes han sido temas que en alguna medida se vinculan, particularmente en cuanto a los obstáculos que enfrentan en sus luchas.

Dentro de los ejemplos del abordaje de esta situación, puede citarse el aporte realizado por Oyarzún Chicuy $(2001,10)$ en su trabajo, quien al referirse sobre el tema de la inclusión de las jóvenes mujeres precisó lo siguiente:

En definitiva, a mi juicio, considerando por un lado la producción del conocimiento de la juventud, por otro el tipo de enfoque que se está utilizando para hacer una lectura 
adecuada de la dimensión de género y el o los tipos de diseño de los instrumentos para diseñar un plan de acción en relación a ellas, queda claro que hasta ahora han prescindido de la mujer joven o la joven mujer: su ausencia en el marco de las políticas sociales y públicas es evidente. La propuesta en este ámbito tendrían que necesariamente pasar por hacer efectivamente una construcción de este sujeto y una adecuada expresión en la política social pública, ya sea al alero de la madre o de la hija.

\section{Inclusión política en Costa Rica}

En el caso de Costa Rica, resultó poco lo encontrado que remitiera directamente a inclusión política. No obstante, la primera referencia que se logró ver en las publicaciones sobre el tema, fue la revisión de las luchas de las mujeres en el país por su inclusión en las estructuras de poder de los partidos políticos, así como las aspiraciones que apuntaban a garantizar la inclusión en las papeletas (cuotas de participación) de las mujeres en puestos de elección popular (Bolaños Barquero, 2011; Zapata Galindo, 2011; Monsiváis, 2013; Rueda-Araya, 2013; Quirós, 2007).

Por ejemplo, parte de estas dinámicas las ha descrito Bolaños Barquero $(2011,3)$, de la siguiente manera:

Para incrementar la representación política de la mujer se ha hecho necesario el uso de sistemas de cuotas, lo cual ha representado un salto cualitativo en la definición de metas, estrategias y métodos. El principal objetivo de los sistemas de cuotas es seleccionar mujeres para puestos en instituciones de gobierno y garantizar que no queden marginadas de la vida pública-política o que su presencia no sea meramente decorativa. En sistemas neutrales con respecto al género, el objetivo es aumentar en números considerables la representación del género que se encuentre infrarrepresentado.

Otras publicaciones mencionaban en sus análisis del tema que en la medida en que se practiquen metodologías o mecanismos de inclusión política efecti- 
va, podría mejorar el orden y el sistema democrático (Martí i Puig y SánchezAncoechea, 2014; Rueda-Araya, 2013).

Como bien ha podido verse en este apartado y el anterior dedicado a Latinoamérica, algunos elementos relacionados con la inclusión política han sido tratados como temas anexos en las publicaciones dedicadas principalmente al estudio de la participación política. Al mismo tiempo, puede denotarse que el tema de juventud e inclusión se ha encontrado sin exploración aparentemente, con la excepción del trabajo de Franceschi Barraza y Chaves Zúñiga (2014).

\section{Confianza y Credibilidad Política}

En aspectos generales, para este apartado, se mantiene la tendencia de estudios mayormente de alcance descriptivo e interpretativo. Los principales focos de interés son temas como la transparencia, la legitimidad y la desconfianza en candidatos y partidos políticos, desconfianza sistema político (democracia) e instituciones políticas.

También, se mantiene la predominancia de trabajos desde un enfoque cualitativo, con la particularidad de que en esta temática en especial más trabajos con un enfoque cuantitativo que en las anteriores. No obstante, es necesario señalar que la población más consultada en esta sección son las personas adultas mediante encuesta, primordialmente.

\section{Confianza política y credibilidad política en América Latina}

Con la lectura de los artículos que se enfocaron en esta temática, pudo constatarse que el uso conceptual realizado de la confianza política inicialmente tiende a ser equiparada con la definición de confianza individual (confianza interpersonal). Sin embargo, luego los estudios centran su atención en la confianza que se deposita: en instituciones y figuras de autoridad; en la capacidad de estos actores políticos de hacer su trabajo; o bien, como parte de uno de los elementos que inciden en la participación política (Rodríguez León, 2003, Rojas y Marín, 2006; González, Carvacho, Manzi, Segovia y Haye, 2008; Montero, Zmerli, y Newton, 2008; Cabasés, Civit y Feixa, 2015).

Otras publicaciones consultadas en las que se incluían personas jóvenes en sus poblaciones y muestras de estudio, sugieren que los países latinoamericanos son la región donde menos confianza se tiene en los partidos políticos y las instituciones encargadas de hacer cumplir leyes. No obstante, la situación en términos de confianza, al parecer, es distinta con los gobiernos locales (Hernández-Bonivento y Güemes, 2014; Brussino, Sorribas y Rabbia, 2009; Corral, 2008; Baeza, 2011; Gillman, 2010). Por ejemplo, Baeza Correa $(2011,84)$ ilustra este último dato de la siguiente forma:

Dos consideraciones previas, una que resulta obvia de la presentación de los datos. No es que la juventud chilena sea desconfiada en particular, sino que en general la po- 
blación latinoamericana, en gran medida, no presenta al-

tos niveles de confianza en los otros.

La importancia capital de conclusiones como esta consiste en que derrumba, por sí sola, una de las aseveraciones que quizás se difunde más desde las posturas adultocentristas; es decir, esa que asegura sin ninguna evidencia que lo pruebe, que la mayoría sino la totalidad de las problemáticas y la falta de "interés" de las sociedades latinoamericanas por la política, recae sobre las juventudes.

En lo que concierne a la credibilidad política, el tema aparece trabajado inicialmente de forma indirecta desde los estudios de marketing; en especial, aquellos orientados a evaluar la credibilidad en materia de medios de comunicación, específicamente en el análisis de la forma cómo estos presentan las informaciones y la confiabilidad que las audiencias les atribuyen vinculado con el "valor de marca" de la empresa, etc. Esta premisa, luego, aparece expuesta en los trabajos que estudian la credibilidad de las instituciones o instancias políticas.

De esa manera, las mismas investigaciones concluyen que cuando una instancia política o un medio de comunicación realizan un trabajo de mejoramiento de su imagen, en ciertas circunstancias, ello se traduce en una mayor confianza y credibilidad por parte de las audiencias (Virriel-Lopez, 2000; Aguirre Ramírez, 2000; Torres-Fragoso, 2008). Por ejemplo, Aguirre Ramírez $(2000,173)$ esquematiza lo anterior planteando la siguiente proposición analítica:

Para concluir, la comunicación política crea la conexión entre el sistema y su entorno, la credibilidad política se genera no a través de spots sino de un trabajo continuo con los diversos sistemas sociales. Desde esta óptica, las ideologías serán necesarias tanto para el partido como para la construcción de una comunicación política adecuada con el entorno.

No obstante, el tema no se agota aquí y otras investigaciones se han enfocado en estudiar primordialmente el marketing político, que se realiza en los partidos políticos. En dichos estudios han encontrado que en su afán por ganar votos en las campañas electorales estas instancias dejan de lado sus posturas ideológicas tradicionales por estrategias de marketing puro, lo cual, a posteriori, repercute en sus dinámicas y estructuras políticas, porque lo que mueve el programa de gobierno es el "mercado político" y no una propuesta programática o un proyecto político claro. (Viñarás Abad, 2013; Murillo, 2015; Kuschick, 2006; Aguirre Ramírez, 2000; Calvo Porral, Martínez Fernández y Juanatey Boga, 2014). 
Siguiendo los artículos revisados, situaciones como estas llevan a que las legitimidades de los discursos y la transparencia percibidas en las acciones de los partidos políticos se vean muchas veces comprometidas. Esto, quizás motivado por el uso de imágenes y contenidos en los mensajes políticos emitidos durante tiempos de campaña electoral, que llegan a ser apreciados por las personas con una considerable distancia con respecto a la realidad cotidiana de las personas (Murillo, 2015; Massal, 2006; Kuschick, 2006).

En algunas investigaciones ha sido posible evidenciar que el tema de la credibilidad política, también, ha sido una inquietud de quienes estudian temas relacionados con la confianza que las personas jóvenes y adultas dan a diversos medios de comunicación, sin olvidar el tema de verles como empresas que venden sus servicios (Arias Robles, 2014).

\section{Confianza política y credibilidad política en Costa Rica}

Para Costa Rica el panorama en este tema no es muy diferente del resto de Latinoamérica porque, tal como sucedió en el caso anterior, según los resultados de las publicaciones revisadas, la confianza política se deposita en primer lugar hacia el sistema democrático o la democracia. Se observa, también, la presencia de una desaprobación o falta de confianza en las instancias o elementos intermedios del sistema, es decir las instituciones y las personas que aplican sus leyes o que velan por el cumplimiento garantías.

Esto sucede con algunas características llamativas, por ejemplo, la evaluación positiva que han recibido en varios estudios y encuestas instituciones como la defensoría de las habitantes o las universidades estatales, en términos de credibilidad y confianza en comparación con las calificaciones casi completamente opuestas que han recibido instancias políticas como la asamblea legislativa, los partidos políticos y las instancias que prestan servicios al público.

Dicha situación, de acuerdo con las autoras y los autores de las publicaciones, se puede atribuir a los problemas en los que dichos actores políticos han incurrido a la hora de generar acuerdos o la forma en cómo los han tomado (Aguilar Carvajal, 2013; Sandoval, González, Carrillo; Calderón y Pernudi. 2002; Chavarría, Alfaro, Carvajal y Ruiz, 2004; González, Carrillo, Pernudi, Solórzano, Juárez y Sandoval, 2003).

Parte de las tendencias antes expuestas, son explicadas por González, CarriIlo, Pernudi, Solórzano, Juárez y Sandoval $(2003,62)$ de la siguiente manera en las conclusiones de su estudio:

Finalmente, otro factor que incide en el enquistamiento de esa antipolítica es la pérdida de credibilidad en la clase política, que en el contexto de la democracia aparece aglutinada y articulada principalmente en los partidos políticos. La credibilidad en la clase política comprende tan- 
to la capacidad que ella desarrolle, a través del mecanismo de partidos políticos (representatividad), para captar y articular los anhelos y las exigencias de la población, como la postulación de un proyecto político histórico, conforme a una aspiración y horizonte ético político susceptibles de ser aceptado por la población como propios. Por eso, en esta ocasión, también se ha consultado a la ciudadanía costarricense respecto de la confianza que deposita en la clase política. Pero las respuestas parecen ser un aviso a estas clases políticas, pues el 94 por ciento de las personas entrevistadas, tanto en la encuesta personal como en la telefónica, han manifestado que tienen poca o ninguna confianza en las clases políticas del país.

El ejemplo anterior no solo deja en claro que la credibilidad de una instancia política es resultado del trabajo que realiza esta para ganarse la confianza de las poblaciones en general, sino también cuando el funcionamiento o los resultados de las gestiones, al interior de una instancia política, no corresponden con las aspiraciones y las demandas más apremiantes de las poblaciones.

La credibilidad es un atributo muy difícil de lograr. Cabe destacar que los estudios antes mencionados en esta sección, también incluían a personas jóvenes dentro de los grupos entrevistados. Se determinó que no había prácticamente diferencias significativas entre los porcentajes sistematizados como resultado del proceso de encuesta. Dicho de otra forma, la falta de confianza política y poca credibilidad política que se les otorga a las instancias políticas en cuestión parecen ser generalizadas.

No obstante, otras investigaciones han aclarado que son las personas de menor grado académico quienes solicitan al gobierno y a las demás instituciones estatales mayor igualdad y honestidad en la función pública, mientras que otros sectores económicos reclaman más libertades individuales.

Al igual que las investigaciones anteriormente citadas, en lo que respecta a las personas jóvenes, los resultados parecen mostrar que estas no se distancian mucho de este tipo de opiniones o exigencias (expresadas por adultos) con respecto a la confianza política en instituciones y gobernantes (Gutiérrez Porras, 2013; Carvajal, 2010 y Vega, 1992; González, Carrillo, Pernudi, Solórzano, Juárez y Sandoval, 2003).

Por último, algunas de las publicaciones revisadas han planteado que diversas acciones y compromisos políticos adquiridos por las clases políticas del 
país en los años 1980 y 1990 han determinado mucho la forma en la que estas han definido las prioridades o los puntos centrales de sus agendas y proyectos políticos desde aquellos años.

Al mismo tiempo, de acuerdo con los autores, se han podido observar, con mayor frecuencia, ataques a la institucionalidad del Estado por grupos políticos determinados, así como situaciones en las que los mecanismos de control de la corrupción se han visto obstaculizados (Chanto Víquez, 2010; Dabene, 1993; Muñoz Guillén, 1999). Precisamente, las investigaciones que trataron este tema han sugerido que podría haber una vinculación entre el acenso de la corrupción con la caída en la credibilidad de las instituciones del sector público.

Como una acotación que ilustra lo anterior, Muñoz Guillén (1999, 42-43), en su artículo, realiza una descripción sobre la forma en la que el discurso sobre la antidrogas utilizado con fines electorales y las diversas presiones de ciertos sectores particulares interesados en el tema. A criterio de la autora, ha vulnerado la credibilidad algunos aspectos de la vida política del país:

El hecho de que esta práctica se haga sentir hasta en las luchas internas de los partidos políticos mayoritarios, sin que se establezca con claridad quién proporciona la información y quién decide el momento de su utilización, debilita la confianza en la democracia. La fuerza legitimadora de la regla mayoritaria pierde su poder fundante, cuando surge la sospecha justificada y probable de que no solamente las decisiones de partidos, gobiernos y parlamentos, sino las propias decisiones mayoritarias de los electores, se ven influidas por el poder publicitario de los medios de información. Estos, por tanto, se vuelven instrumentos de poder privado; más aún -cuando por la naturaleza ilegal y clandestina del narcotráfico- las fuentes originales de la información son agencias de inteligencia de gobiernos extranjeros.

Con los señalamientos de la autora, puede inferirse que, factores como las influencias externas o aquellas ya incorporadas a las instancias políticas que no responden necesariamente a los intereses de la agrupación, la mediatización de las pugnas internas en el manejo de temas de gran trascendencia para la sociedad costarricense, la definición de los proyectos políticos y sus objetivos determinados a partir de dichas situaciones sin tomar en cuenta una profunda exploración del Estado o la realidad del país, aumentan las po- 
sibilidades de que ante la sensación de desorden y falta de interés por las necesidades de las personas, la poca credibilidad política sea el resultado más esperable para los partidos políticos u instancias similares.

\section{Conclusiones}

\section{Acerca de las relaciones entre conceptos encontradas en el análisis básico con Atlas.ti 7}

Es necesaria la acotación inicial de que la definición de comportamiento político aquí utilizada, parte de la conceptualización y los aportes de Anduiza Perea y Bosch Gardella (2004). En el mismo, se detalla que este término comprende el estudio de las relaciones que los distintos actores sociales entablan o mantienen con el sistema político, de manera que estas relaciones se materializan en las condiciones y los procesos en los que sucede la participación de las personas. Al mismo tiempo los autores insisten que este fenómeno, no es homogéneo, por lo que guarda en sí una variedad de matices que también suelen ser objeto de estudio.

Además, se ha explicado, en el apartado metodológico de este artículo, que el análisis de las publicaciones seleccionadas se ha realizado con el programa informático de análisis cualitativo Atlas.ti 7, el cual permite realizar un análisis sistemático de datos cualitativos de gran calado. Por ello, vale la pena empezar la exposición de las conclusiones con las principales relaciones entre conceptos encontradas a partir del trabajo realizado en el nivel básico de análisis.

En ese entendido, los conceptos, principalmente estudiados en este artículo, fueron los siguientes: participación, inclusión, confianza, credibilidad y juventud. Cada uno de estos términos formó parte de varias familias de códigos a partir de los cuales se analizaron en este primer nivel de análisis básico.

Al realizar una exploración con el programa de las coocurrencias presentes entre las grandes familias de códigos, se logró evidenciar que en los artículos estudiados existe una fuerte relación entre la familia de códigos de participación política e inclusión política (442 referencias), tanto en las publicaciones nacionales y extranjeras.

Todo lo anterior, está marcado, principalmente, por las observaciones al incumplimiento del principio de igualdad y no discriminación y varias referencias al señalamiento de una falta de condiciones para el ejercicio efectivo de participación ciudadana. Al mismo tiempo, en algunos de estos estudios, se habla de personas jóvenes en sus poblaciones. No obstante, no constituyen el foco principal de su interés analítico.

Se pueden destacar dos relaciones conceptuales más: la primera entre la familia de códigos de participación política con la de confianza política y credibilidad política (265 referencias), seguida por la familia de códigos de inclusión política con la de credibilidad política (154 referencias). 
En el caso de la primera, la fuerte coocurrencia encontrada podría sugerir que las autoras y los autores de las investigaciones revisadas, se han inclinado a rastrear cómo la participación política podría estar ligada a la confianza política que las personas tengan de un sistema político y la credibilidad política que proyecten sus instituciones políticas e instancias estatales.

La relación no se acaba ahí, pues varios conceptos individuales pertenecientes al grupo de confianza y credibilidad política se relacionaron fuertemente con la familia de códigos de participación política, los cuales en orden de coocurrencia para este análisis son los siguientes: desconfianza partidos políticos (66 referencias), desconfianza del sistema político (63 referencias), desconfianza en instituciones públicas (49 referencias), confianza sistema político (40 referencias) y desconfianza en candidatos (39 referencias).

Con estos resultados, y considerando que la mayoría de los estudios a los que corresponden estas coocurrencias incluyeron en sus muestras a poblaciones de varios grupos de edad (18 años en adelante), podría inferirse que tanto en Costa Rica como en América Latina se tiene un profundo sentimiento de que los sistemas basados en democracias representativas y los partidos políticos no están cumpliendo con su labor fundamental, es decir canalizar las solicitudes e inquietudes de sus ciudadanos, ni con los proyectos políticos de tiempos electorales, ni con los mecanismos específicos destinados a estos efectos.

Mientras que la relación entre los conceptos de inclusión y credibilidad política, por la naturaleza de los conceptos, se podría estar señalando que las investigadoras y los investigadores, quienes se dedican a estos temas, estarían si la presencia de mecanismos de inclusión efectiva tendría alguna relación con la confianza y la credibilidad política de diversas instancias políticas.

En cuanto a juventud, como categoría conceptual, tiene una relación poco menor con la familia de códigos de Participación política (95 referencias), por lo que si se compara con las relaciones encontradas con las otras familias de códigos, resulta en un vacío presente en la investigación del comportamiento político. Dicho de otro modo, podría concluirse que falta más investigación sobre las relaciones que las personas jóvenes entablan con los sistemas políticos tanto en Costa Rica como en el resto de Latinoamérica.

Esto deja ver, por ahora, que no se han logrado superar o eliminar las barreras que impiden la inclusión y la participación política de muchos sectores de las sociedades latinoamericanas.

\section{Conclusiones globales a partir del análisis interpretativo de los resultados de este estudio}

\section{Participación política y juventud:}

Uno de los nodos centrales de las investigaciones relacionadas con este tema, es casi siempre responder por la forma en la que sucede, los sujetos 
implicados y los factores que explican las dinámicas de involucramiento de la ciudadanía, así como sus consecuencias.

En el tema de la participación política, se tiende a vincular su ocurrencia únicamente como aquellos procesos de involucramiento y acciones que tienen lugar en los espacios formalizados e institucionalizados para ello. Sin embargo, no son todos los espacios de participación oficial ni todos los actores políticos los que cuentan con los recursos necesarios para desarrollarse a cabalidad.

En este sentido, partiendo de todos los datos antes expuestos en este artículo, actores políticos como las personas jóvenes y las mujeres forman parte de esos integrantes del sistema político que encuentran importantes limitaciones para el desenvolvimiento de sus acciones y proyectos.

Ante esto, una de esas barreras a las que se enfrentan las personas jóvenes está formada por posturas adultocentristas, las cuales son reproducidas tanto por personas adultas como personas jóvenes dentro de las estructuras político-partidarias. Esta limitante tiene alcances hasta aquellas personas que toman decisiones con respecto a los ámbitos desde los cuales la juventud puede participar.

De acuerdo con los datos de las investigaciones analizadas, que incluían a personas jóvenes en sus muestras o unidades de estudio, es palpable que las personas jóvenes tanto de Costa Rica como de Latinoamérica, conciben el campo de la política formal como un campo que les excluye de toda posibilidad de participar y ajeno a muchos de los intereses populares.

De esta forma, al menos en el sector de la participación político-electoral, las barreras que afrontan las personas jóvenes se materializan en la delimitación de temas y puestos específicos de participación, tales como el deporte, la cultura, la recreación y puestos de elección popular con poca o ninguna posibilidad de resultar electos.

Finalmente, vale la pena rescatar entre los eventos tratados en las investigaciones revisadas sobre participación política en Costa Rica, el proceso de referendo de octubre de 2007, por el desenvolvimiento de las personas jóvenes que se involucraron junto con personas de otros grupos etarios, provenientes de diversas organizaciones y colectivos sociales. Ello ha sido, quizás, uno de los mejores ejemplos movilización y acción política de la historia reciente. En los Comités Patrióticos se aglutinaron personas de todas las edades, pero las personas jóvenes jugaron un papel importante en su repercusión en la realidad nacional.

\section{Inclusión política y juventud}

En este caso, se ha podido ver que existe una fuerte relación entre los conceptos de participación e inclusión y que esta relación parte de las preocupaciones académicas que se han centrado en el cumplimiento del derecho a ser tomado en cuenta en el marco de la participación política. Dicha correspondencia no es gratuita, pues entre tanto se cuente con mecanismos políti- 
cos de inclusión política, la participación política de actores políticos como las personas jóvenes pueden verse más potenciadas.

Sin embargo, aunque se cuenta con procesos de inclusión planteados para las juventudes en algunas de las legislaciones a nivel general (incluida la de Costa Rica), su concreción efectiva está todavía complicada por las barreras extrarreglamento, que parecen estar presentes en los procesos de toma de decisiones vinculantes.

El análisis aquí realizado ofrece resultados que bien podrían dar luces sobre la paradoja compleja que afrontan las juventudes que participan en los entornos políticos formales e informales. Dicha situación se comprende del estatus legal (en la mayoría de los países), que les faculta como sujetos de derechos con facultades para participar y ser incluidos dentro de las discusiones y procesos políticos que determinen tanto su futuro como colectivo social, como aquellas dinámicas determinantes para la realidad o el futuro del país, pero con la limitante de ser incluidos en escaños y espacios en los cuales sus propuestas e inquietudes tienen poca o ninguna repercusión en el desarrollo de dichos procesos decisionales.

Si se toma en cuenta esta situación de las personas jóvenes en la actualidad, cabría echar una mirada atenta, en términos de inclusión política, a las luchas emprendidas por las mujeres por espacios de incorporación efectiva en los procesos electorales y de toma de decisiones vinculantes que sucedieron en diversos países latinoamericanos desde inicios del siglo XX, porque conociendo y teniendo en consideración los procesos por los cuales los colectivos femeninos tuvieron que pasar, estas experiencias podrían coadyuvar en la posibilidad de que otros grupos y sectores de la sociedad costarricense, como lo son las personas jóvenes, sigan un camino similar (y adecuado a sus realidades).

Lo anterior tiene su fundamento en el hecho expuesto en los datos presentados en este artículo, que parecen sugerir que las condiciones de exclusión social y política a las que se enfrentaron los colectivos de mujeres y que las llevaron en décadas pasadas a exigir sus derechos políticos y sociales, son similares a las dificultades en enfrentan en la actualidad las personas jóvenes.

\section{Confianza política, credibilidad política y juventud}

Luego del análisis en profundidad de las investigaciones dedicadas al estudio de la confianza política, logra verse que la poca confianza política que las juventudes han demostrado por las clases políticas, los partidos políticos y algunas instituciones del estado, no es una realidad ajena de la que se comparte con los demás sectores de la sociedad costarricense y latinoamericana, pues los resultados que señalan el descontento político se encontraron en publicaciones de varias latitudes.

En ampliación a este aspecto, se habló en los estudios analizados que la confianza política en América Latina es baja y esto no resulta para nada descabellado si por un momento se recuerda que en el pasado de la región en la 
mayor parte de los países se han dado procesos de intervención, obstrucción o ataques directos a los sistemas político democráticos por actores internos y externos. Asimismo, quizás como resultado de estos eventos y procesos contemporáneos particulares en cada país, la confianza política se ve afectada. No obstante, no todo es desesperanza en este punto pues tanto las personas jóvenes como las personas adultas siguen confiando en los sistemas democráticos como una forma de garantizar en buena medida la convivencia y la resolución de los asuntos públicos.

En cuanto al tema de la credibilidad política, los estudios encontrados en la región tienen como marco de referencia el marketing político, el cual consiste en la aplicación de las técnicas de publicidad y venta de marcas comerciales en el diseño y puesta en marcha de las campañas electorales de los partidos políticos.

Este detalle constitutivo de su metodología y fundamentación, ha implicado que, en el ejercicio de los partidos políticos, se llegue a equiparar a las personas candidatas con productos comerciales y campañas electorales con estrategias de publicidad orientadas a las demandas del mercado electoral. Se requiere de una multiplicidad de recursos discursivos y de imagen muy similares a los que aplican empresas o industrias que venden un producto o intentan posicionar una marca.

En lo que respecta a la credibilidad política que las instituciones políticas intentan generar en los diferentes grupos de la sociedad, falta exploración que enfatice las estrategias que se pueden estar usando para acercarse a las personas jóvenes.

No obstante, con los datos disponibles en esta exploración, se puede inferir que prevalece un tratamiento y un análisis que insisten en ver a las personas jóvenes desde una suerte de discurso de la falta; es decir, enfatizando las carencias que supuestamente poseen con respecto a otros grupos de personas, como por ejemplo los adultos. De esta forma, aseveraciones sobre la personalidad y la carencia de sentido o un rumbo definido son recursos utilizados, en la mayoría de los casos, para intentar reafirmar los discursos sobre juventud desde el "deber ser adulto".

Finalmente, puede afirmarse que uno de los principales aportes que quizás haya indicado el análisis de los estudios para este artículo, es que confianza política y credibilidad, aunque son dos conceptos relacionados, son términos diferenciables cuando se trata de analizar determinadas características del comportamiento político. Lo anterior porque las relaciones de confianza (o el establecimiento de esta) y las que se ponen en marcha para generar credibilidad no son homólogas, además aparentemente ambos procesos tampoco son simultáneos. 


\section{Bibliografía}

Abarca, Rocío. 2014. «Entre la participación y la voluntad política. La iniciativa popular y el caso del proyecto de ley gestión integral del recurso hídrico en Costa Rica» Anuario Centro de Investigación y Estudios Políticos, 3(0): 148-179. Acceso el 10 de febrero de 2016 en http://revistas.ucr.ac.cr/index.php/ciep/article/view/14645/14621

Aguilar Carvajal, Luis. 2013. Percepción y Actitudes De La Población Costarricense Hacia La Política y La Democracia. IDESPO. Acceso el 15 de marzo de 2016 de http://repositorio.una.ac.cr/handle/11056/7335?show=full.

Aguilera Ruiz, Oscar. 2010. «Cultura política y política de las culturas juveniles» Utopía y Praxis Latinoamericana, 15: 91-102. Acceso el 2 febrero 2016 de http://www.redalyc.org/articulo.oa?id=27915750007

Aguirre Ramírez, Laura Marina. 2000. «La importancia de las ideologías de los partidos políticos en la propaganda electoral.» Revista Mexicana de Ciencias Políticas y Sociales, 44: 165-174. Acceso el 8 de febrero de 2016 de http://www.redalyc.org/articulo.oa?id=42118013

Alejandro Ramos, Gonzalo y Claudio, Escobar Cruz. 2009. «Jóvenes, ciudadanía y participación política en México» Espacios Públicos 12: 103-122. Acceso el 8 de febrero de 2016 de http://www.redalyc.org/articulo.oa?id=67611350007

Alpízar, Carlomagno. 2015. "«Análisis Estadístico Del Abstencionismo En Las Elecciones Presidenciales De Costa Rica, 2014». Revista De Ciencias Económicas, 33(1): 75-87. Acceso el 8 de marzo de 2016 de http://revistas.ucr.ac.cr/index.php/economicas/article/view/19972/21615

Alvarenga Venutolo, Patricia. 2012. «Sexualidad Y Participación Política Femenina En La Izquierda Costarricense» Cuadernos Inter.C.A.Mbio Sobre Centroamérica Y El Caribe, 4(5): 231-267. Acceso el 26 de febrero de 2016 de http://revistas.ucr.ac.cr/index.php/intercambio/article/view/3908/3779. 
Álvarez Rudín, Mercedes. 2011. «Movimientos Sociales Y Participación Política: El Movimiento Contra EI TLC En La Campaña Del Referéndum 2007 En Costa Rica». Anuario De Estudios Centroamericanos, 37 (1-2): 201-203. Acceso el 5 de febrero de 2016 de http://revistas.ucr.ac.cr/index.php/anuario/article/view/1125/1185.

Álvarez Torres, Cheryl y Alejandro Monsiváis Carrillo. 2015. «Democracia, Capacidades Deliberativas E Inclusión Política Juvenil: El Caso De Baja California». Revista Mexicana De Ciencias Políticas Y Sociales, 60 (225). Acceso el 28 de marzo de 2016 de http://www.redalyc.org/articulo.oa?id=42141200007

Amador, Bech. 1995. «La construcción de la credibilidad como forma discursiva e imaginaria» Revista Mexicana de Ciencias Políticas y Sociales, 40(162). Acceso el 15 de marzo de 2016 de http://www.revistas.unam.mx/index.php/rmcpys/article/view/49665

Anduíza Perea, Eva y Agustí Bosch Gardella. 2004. Comportamiento político y electoral. Barcelona: Editorial Ariel S.A.

Angúlo Brenes, Sonia. 2010. «Posibilidades y limitaciones para la participación social desde la perspectiva de diferentes actores locales» Revista Reflexiones, 89 (1). Acceso el 2 de marzo de 2016 de http://revistas.ucr.ac.cr/index.php/reflexiones/article/view/11571.

Araya Alpízar, Carlomagno. 2015. «Análisis Estadístico Del Abstencionismo En Las Elecciones Presidenciales De Costa Rica» Revista De Ciencias Económicas, 33(1): 63. Universidad de Costa Rica. Acceso el 2 de marzo de 2016 de doi:10.15517/rce.v33i1.19972

Arias Robles, Félix. 2014. «La credibilidad de los contenidos informativos en Internet para los 'nativos digitales': estudio de caso.»Palabra Clave, 17: 875-894. Acceso el 15 de marzo de 2016 de http://www.redalyc.org/articulo.oa?id=64931834012 
Baeza Correa, Jorge. 2011. «Juventud y Confianza Social En Chile» Última Década: 73-92. Acceso el 15 de marzo de 2016 de http://www.redalyc.org/articulo.oa?id=19518452007

Ballester, Marta e Ismael Blanco. 2011. «¿Participar para transformar? La experiencia de los Presupuestos Participativos en la provincia de Barcelona» Gestión y Análisis de Políticas Públicas: 117-144. Acceso el 16 de marzo de 2016 de http://www.redalyc.org/articulo.oa? $\mathrm{id}=281521735005$

Barrancos, Dora. 2013. «Participación Política Y Luchas Por El Sufragio Femenino En Argentina (1900-1947)». Cuadernos Inter.C.A.Mbio Sobre Centroamérica Y El Caribe, 11(1): 15-26. Acceso el 10 de marzo de 2016 de http://revistas.ucr.ac.cr/index.php/intercambio/article/view/14232/13524

Barry, Carolina .2006. Puntos y contrapuntos de la militancia femenina peronista en el barrio de Belgrano (1946-1955). Centro de Estudios de Historia Política, Universidad Nacional Del General San Martín. Acceso el 14 de marzo de 2016 de http://www.unsam.edu.ar/escuelas/politica/centro_historia_politica/mate rial/147.pdf

Beltrán, Oscar .2005. «Revisiones sistemáticas de la literatura. Rincón Epidemiológico» Revista Colombiana De Gastroenterología, 20(1): 6069. Acceso el 2 febrero 2017 de http://www.scielo.org.co/scielo.php? script=sci_arttext\&pid=S0120-99572005000100009

Blanco Lizano, Randall. 2002. «Los Partidos Cantonales En Las Elecciones Municipales De Costa Rica: 1949-2002. Una Interpretación Sociológica». Anuario De Estudios Centroamericanos, 28(1-2): 161186. Acceso el 14 de marzo de 2016 de http://revistas.ucr.ac.cr/index.php/anuario/article/view/1872/1838.

Bolaños Barquero, Arlette. 2011. «Las Cuotas De Participación Política Y La Inclusión De Las Mujeres En La Vida Pública En Costa Rica, 1996- 
2003» Diálogos Revista Electrónica, $5 \quad\left(\begin{array}{lllll}1 & \text { y } & 2\end{array}\right)$. http://revistas.ucr.ac.cr/index.php/dialogos/article/view/6233.

Boneti Martí, Jordi. 2012. «El territorio como espacio de radicalización democrática. Una aproximación crítica a los procesos de participación ciudadana en las políticas urbanas de Madrid y Barcelona. Athenea Digital» Revista de Pensamiento e Investigación Social, 12: 15-28. Acceso el 2 de marzo de 2016 de http://www.redalyc.org/articulo.oa? id $=53723265002$

Botero Gómez, Patricia; Juliana Torres Hincapié y Sara Alvarado. 2008. «Perspectivas teóricas para comprender la categoría participación ciudadana-política juvenil en Colombia.» Revista Latinoamericana de Ciencias Sociales, Niñez y Juventud 6: 565-611. Acceso el 5 de febrero de 2016 de http://www.redalyc.org/articulo.oa?id=77360205

Brussino, Silvina; Patricia Sorribas y Hugo Rabbia. 2009. «Perfiles Sociocognitivos de la Participación Política de los Jóvenes» Interamerican Journal of Psychology, 43: 279-287. Acceso el 5 de febrero de 2016 de http://www.redalyc.org/articulo.oa? $\mathrm{id}=28412891009$

Bústos Pizarro, Patricio. 1997. «Jóvenes: Reflexiones en torno al tema de la participación y la política» Última Década, 7. Acceso el 17 de febrero de 2016 de http://www.redalyc.org/articulo.oa?id=19500707

Cabasés, Ángels; Roger Civit y Carles Feixa. 2015. «Jóvenes y confianza política en un contexto de desestabilización social e institucional. Un estudio comparativo en países de la cuenta del mediterráneo» Última Década, 42: 149-185. Acceso el 15 de marzo de 2016 de http://redalyc.org/articulo.oa?id=19542273008

Calderón, María. 2011. «La Construcción Del Discurso Estatal En El Ecuador: Etnicidad Y Difusión De La Legitimidad En Las Primeras Décadas Del Siglo XX» Estudios 0 (24): 75-89. Acceso el 16 de marzo 
http://revistas.ucr.ac.cr/index.php/estudios/article/view/22778/22944 .

Calderón, Odalía; Irma Sandoval; Dionisio Alfaro; Hugo González y María Carrillo. 2013. «La población costarricense del gran área metropolitana frente a los gobiernos locales» IDESPO. Acceso el 15 de marzo de 2016 de http://repositorio.una.ac.cr/handle/11056/7281

Calvo de Mora, Javier. 2011. «Aspectos críticos del liderazgo institucional en la educación» Revista Electrónica Actualidades Investigativas en Educación, 11: 1-29. Acceso el 15 de marzo de 2016 de http://doi.org/10.15517/aie.v11i2.10210

Calvo Porral, Cristina, Alejandro Martínez Fernández y Oscar Juanatey Boga. 2014. «La credibilidad de los medios de Comunicación de masas: una aproximación desde el Modelo de Marca Creíble.» Revista Brasileira de Ciências da Comunicação, 37: 21-49. Acceso el 10 de marzo de 2016 de http://www.redalyc.org/articulo.oa?id=69832559002

Canto Chac, Manuel. 2008. «Gobernanza y participación ciudadana en las políticas públicas frente al reto del desarrollo» Política y Cultura, (30) 937. Acceso el 15 de marzo de 2016 de http://www.redalyc.org/articulo.oa?id=26711160002

Carmona, Rodrigo y Carlos Martínez. 2013. «El presupuesto participativo como herramienta de transformación social, política e institucional. Un balance en el escenario argentino reciente» Revista ABRA, 33 (47): 2636. Acceso el 15 de marzo de 2016 de http://www.revistas.una.ac.cr/index.php/abra/article/view/5585/5428

Carrasco Azzini, Giovanni. 2010. «Participación y tendencias políticas en estudiantes universitarios: el caso de la Universidad de Chile». Última Década, (32): 85-103. Acceso el 15 de marzo de 2016 de http://www.redalyc.org/articulo.oa?id=19515560005

Carrillo Padilla, José. 2014. «Reseña Del Libro De Patricia Alvarenga: Identidades En Disputa. Las Reinvenciones Del Género Y La 
Sexualidad En La Costa Rica De La Primera Mitad Del Siglo XX» Cuadernos Inter.C.A.Mbio Sobre Centroamérica Y El Caribe, 11(1): 227-230. Acceso el 2 de marzo de 2016 de http://revistas.ucr.ac.cr/index.php/intercambio/article/view/14241/13533.

Casas, Ernesto. 2009. «Representación política y participación ciudadana en las democracia» Revista Mexicana de Ciencias Políticas y Sociales (205): 59-76. Acceso el 10 de marzo de 2016 de http://www.redalyc.org/articulo.oa?id=42112421004

Castoriadis, Cornelius. 1983. La institución imaginaria de la sociedad. Barcelona: Tusquets Editores.

Castoriadis, Cornelius. 2004. Sujeto y verdad en el mundo social. Buenos Aires: Fondo de Cultura Económica, S.A.

Chanto Víquez, Raquel .2010. «Legislación de control de la corrupción y el gasto público y sus efectos sobre la política pública». Tesis de grado para optar al título de Licenciada en Derecho. Facultad de Derecho, Universidad de Costa Rica. Acceso el 15 de marzo de 2016 de http://iij.ucr.ac.cr/sites/default/files/documentos/t10legislacion_de_control_de_la_corrupcion_y_el_gasto_publico.pdf

Chavarría, Vilma, Norman Alfaro, Irma Carvajal, and Rodrigo Ruiz. 2004. «Percepción De La Población Costarricense Frete Al Gobierno Y La Asamblea Legislativa». IDESPO. Acceso el 10 de marzo de 2016 de http://repositorio.una.ac.cr/handle/11056/7304

Chinchilla, Lucía, Paula Castro, Claudia Cisterna y Maureen Calvo. 2013. «La Identidad Del Adolescente Y Su Relación Con El Imaginario Nacional Costarricense» Actualidades Investigativas en Educación, 14(2). Acceso el 10 de febrero de 2016 de http://revistas.ucr.ac.cr/index.php/aie/article/view/14798/18349.

Corral, Margarita. 2008. «(Des)confianza en los partidos políticos en América Latina». Revista de Ciencia Política, 28(2). Acceso el 5 de marzo de 2016. http://www.redalyc.org/articulo.oa?id=32414669009 
Dabene, Olivier. 1993. «La Invención Y Remanencia De Una Crisis: Centroamérica En Los Años 80». Anuario De Estudios Centroamericanos, 19(2): 25-50. Acceso el 15 de marzo de 2016 de http://revistas.ucr.ac.cr/index.php/anuario/article/view/2668/2619.

Díaz Gómez, Álvaro y Liliana Salamanca Aragón. 2012. «Los jóvenes son sujetos políticos... a su manera» Utopía y Praxis Latinoamericana, 17(57) 109-117. Acceso el 14 de marzo de 2016 de www. redalyc.org/articulo.oa? $\mathrm{id}=27922814010$

Duarte, Quapper, Claudio. 2012. «Sociedades adultocéntricas: Sobre sus orígenes y reproducción». Última década, 36: 99-125.

Ferreira Cypriano, Breno. 2014. «La idea feminista de la política desde el sur global». Revista Estudios Feministas, 22: 627-635. Acceso el 2 de febrero de 2016 de http://www.redalyc.org/articulo.oa?id=38131661014

Flick, Uwe. 2015. El diseño de investigación cualitativa. Madrid, España: Ediciones Morata S.L.

Fouce, José. 2008. «Las viejas y las nuevas formas de participación sociopolítica» Investigación \& Desarrollo, 16(2) 262-277. Acceso 26 de febrero de 2016 de http://www.redalyc.org/articulo.oa?id=26816209

Franceschi Barraza, Hannia y María Chaves Zúñiga. 2014. «Juventudes rurales y participación: ¿Un derecho con asidero real o un interés gubernamental de participación restringida?» Pensamiento Actual, 13(20). Acceso el 10 de marzo de 2016 de http://revistas.ucr.ac.cr/index.php/pensamiento-actual/article/view/15020

Friese, Susanne. 2015. ATLAS.ti 7: User Guide and Reference. Berlin: ATLAS.ti Scientific Software Development GmbH. Acceso el 10 de marzo de 2016 de http://downloads.atlasti.com/docs/manual/atlasti_v7_manual_en.pdf? _ga=1.236846337.1690687283.1486658512 
Gillman, Anne. 2010. «Juventud, Democracia y Participación Ciudadana en el Ecuador». Revista Latinoamericana de Ciencias Sociales, Niñez y Juventud, 8: 329-345.Acceso 25 de febrero de 2016 de http://www.redalyc.org/articulo.oa?id=77315079016

Godoy Ramos, Carmen. 2013. «El Estado chileno y las mujeres en el siglo XX. De los temas de la mujer al discurso de la igualdad de géneros» Diálogos Revista Electrónica de Historia, 14: 97-123. Acceso el 2 de marzo de 2016 de http://www.redalyc.org/articulo.oa?id=43925651002

González Salcedo, Antonia. 2011. «Los desafíos de la participación ciudadana local. Un estudio comparado entre las ciudades de Madrid y Helsinki» Revista del CLAD Reforma y Democracia, (49): 203-240. Acceso el 14 de maro de 2016 de http://redalyc.org/articulo.oa? id $=357533681007$

González Sancho, Roy y Evita Henríquez Cáceres. 2014. «Alcances y limitaciones de la participación juvenil en los espacios estipulados por la Ley General de la Persona Joven: Asamblea Nacional de la Red Consultiva de la Persona Joven y los Comités Cantonales de la Persona Joven». Programa Agenda Joven, Universidad Estatal a Distancia.

González Suárez, Mirta. 2006. «Agenda Política del Movimiento de Mujeres. Demandas de Inicios del Siglo XXI» Reflexiones, 90(1): 9-22. Acceso el 16 de marzo de 2016 de http://revistas.ucr.ac.cr/index.php/reflexiones/article/view/11438

González, Hugo; Mariam Carrillo; Vilma Pernudi; Norman Solórzano; Oscar Juárez e Irma Sandoval. 2003. «Percepción de la población costarricense sobre la situación socioeconómica y política del pais (pobreza, calidad de vida y confianza institucional)»IDESPO. Acceso el 16 de marzo de 2016 de http://repositorio.una.ac.cr/bitstream/handle/11056/7271/perspec19.pdf ?sequence=1 
González, Roberto; Héctor Carvacho; Jorge Manzi; Carolina Segovia y Andrés Haye. 2008. «Confianza en instituciones políticas en Chile: un modelo de los componentes centrales de juicios de confianza» Revista de Ciencia Política, 28(2). Acceso el 14 de marzo de 2016 de http://www.redalyc.org/articulo.oa?id=32414669002

Gordon, Sara. 2005. «Confianza, capital social y desempeño de organizaciones» Revista Mexicana de Ciencias Políticas y Sociales, 47: 41-55. Acceso el 5 de marzo de 2016 de http://www.redalyc.org/comocitar.oa?id=42119303

Gutiérrez Briceño, Thaís e Isabel Rodríguez Colmenares. 2012. «Prerrequisitos generales para la formulación de políticas sociales de inclusión: Caso Venezuela» Revista de Ciencias Sociales, 18(4): 628640. Acceso el 28 de marzo de 2016 de http://www.redalyc.org/articulo.oa?id=28025469005

Gutiérrez Porras, Blanca. 2013. «Presentación: Percepciones De Políticas Públicas Para La Juventud Costarricense». IDESPO. Acceso el 15 de marzo de 2016 de http://repositorio.una.ac.cr/handle/11056/7347

Hatibovic Díaz, Fuad y Juan Sandoval Moya. 2010. «Socialización política y juventud: el caso de las trayectorias ciudadanas de los estudiantes universitarios de la región de Valparaíso» Última Década (32): 11-36 acceso el 15 de marzo de 2016 de http://www.redalyc.org/articulo.oa? id=19515560002

Hernández Bonivento, José y Cecilia Güemes. 2014. «Confianza, instituciones informales y políticas públicas, una compleja relación pendular» Gestión y Análisis de Políticas Públicas, 12. acceso el 16 de marzo de 2016 de http://www.redalyc.org/articulo.oa?id=281532956007

Holzner, Claudio A. 2007. «Voz y voto: participación política y calidad de la democracia en México» América Latina Hoy, (45): 69-87. Acceso el 15 de marzo de 2016 de http://www.redalyc.org/articulo.oa?id=30804504 
Jensen Pennington, Henning y Domingo Campos Ramírez. 1991. «Conciencia Cotidiana Y Actitudes Sociopolíticas. La Representación Social De La Democracia». En: Villasuso, J.M. (Comp.). Costa Rica: El Nuevo Rostro. San José: http://www.kerwa.ucr.ac.cr/handle/10669/11184.

Kuschick, Murilo. 2006. «Persuasión y marketing en la elección del Estado de México» Espacios Públicos, 9(18): 97-111. Acceso el 15 de marzo de http://www.redalyc.org/articulo.oa?id=67601807

Lafuente Ibáñez, Carmen; Marín Egoscozábal, Ainhoa. 2008. «Metodologías de la investigación en las ciencias sociales: Fases, fuentes y selección de técnicas» Revista Escuela de Administración de Negocios: 5-18. Acceso el 2 de febrero de 2017 de http://www.redalyc.org/pdf/206/20612981002.pdf

Ley N 8261. Diario Oficial La Gaceta, San José, Costa Rica, 2 de mayo del 2002.

Ley N 8261. Diario Oficial La Gaceta, San José, Costa Rica, reformas del 8 de julio del 2013.

López Serrano, Javier y Jesús López Serrano. 2009.« La participación política ciudadana; sus límites y controles institucionales en el caso mexicano» Estudios Políticos, 9(16): 9-45. Acceso el 16 de marzo de 2016 de http://www.redalyc.org/articulo.oa?id=426439540001

Lozano Ardila, Martha. 2008. «Los procesos de subjetividad y participación política de estudiantes de psicología de Bogotá» Diversitas: Perspectivas en Psicología, 4(2): 345-357.accesado el 28 de marzo de 2016 de http://www.redalyc.org/html/679/67940210/index.html

Manterola, Carlos, Paula Astudillo, Esteban Arias y Nataniel Claros. 2013. «Revisiones Sistemáticas de la Literatura. Qué Se Debe Saber Acerca De Ellas». Cirugía Española, 91(3): 149-155. Elsevier BV. doi:10.1016/j.ciresp.2011.07.009. 
Marín, Sandra y Miguel Rojas López. 2006. «Aproximaciones a la medición de confianza» Dyna, 73(150): 119-130. Acceso el 28 de marzo de 2016 de http://www.redalyc.org/articulo.oa?id=49615016

Martí i Puig, Salvador y Diego Sánchez-Ancochea. 2014. «La transformación contradictoria: democracia elitista y mercado excluyente en Centroamérica» Anuario de Estudios Centroamericanos, 40(19): 14917. Acceso el 11 de marzo de 2016 de http://www.redalyc.org/articulo.oa?id=15233350008

Martínez Labrín, Soledad, Enrique Blanco Hadi; Fernando Farías Olavarría; Cristian Orellana Fonseca; Gabriel Pérez Díaz; Héctor Cárcamo Vásquez y Bruno Bivort Urrutia. 2015. «Formación ciudadana y participación política en jóvenes de la Universidad del Bío-Bío, Chile». Civilizar Ciencias Sociales y Humanas, 28 (15): 119-133. Acceso el 2 de febrero de 2016 de http://www.redalyc.org/articulo.oa? id $=100241608009$

Massal, Julie. 2006. «El papel de los movimientos sociales en la consolidación democrática: reflexiones alrededor del caso ecuatoriano en perspectiva comparada» Colombia Internacional: 108-127. Acceso el 28 de marzo de 2016 http://www.redalyc.org/articulo.oa?id=81206306

Molina Vega José y Carmen Pérez Baralt (2000). Participación Política. En: Diccionario Electoral. Instituto Interamericano de Derechos Humanos (IIDH). San José: IIDH.

Molina, Juan. 2000. «Juventud y tribus urbanas» Última Década (13) 121-140 acceso el 15 de marzo de 2016 de http://www.redalyc.org/articulo.oa? $\mathrm{id}=19501306$

Monsiváis Carrillo, Alejandro. 2013. «La democracia como política pública: oportunidades para el fortalecimiento democrático». Revista de Estudios Sociales, (3): 25-38. Acceso el 23 de febrero de 2016 de http://www.redalyc.org/articulo.oa?id=81529190003 
Montalvo, Daniel. 2008. «Participación ciudadana en sesiones municipales» Revista de Ciencia Política 28: 219-227. Acceso el 14 de marzo de 2016 de http://www.redalyc.org/articulo.oa?id=32414669012

Montero, José; Sonja Zmerli, y Ken Newton. 2008. «Confianza social, confianza política y satisfacción con la democracia.» Revista Española de Investigaciones Sociológicas: 11-54. Acceso el 5 de marzo de 2016 de http://www.redalyc.org/articulo.oa?id=99715236001

Mora, Virginia. 2001. «Mujeres, Política Y Ciudadanía. Las Reformistas En La Campaña Nacional De 1923». Revista De Historia 0 (38). Acceso el 16 de marzo de 2016 de http://www.revistas.una.ac.cr/index.php/historia/article/view/2031/1929.

Morales Diez de Ulzurrun, Laura. 2001. «Participación política y pertenencia a grupos políticos: los límites de las explicaciones individuales y la necesidad de considerar el contexto político». Revista Española de Investigaciones Sociológicas (94): 153-184. Acceso el 28de marzo de 2016 de http://redalyc.org/articulo.oa?id=99717902006

Morales Ramírez, María, Marianella Castro-Pérez y Marianela Bolaños-Mora. 2015. «Perspectiva del estudiantado universitario de las diversas carreras de la Universidad Nacional acerca de la democracia en la familia, el centro educativo y el país» Revista Electrónica Educare 19(1): 183-219. Acceso el 16 de febrero de 2016 de http://www.redalyc.org/articulo.oa?id=194132805011

Morales Rojas, Carla. 2014. «Las cuotas mínimas de participación política: mecanismos para aumentar la representación política de las mujeres» Trabajo Final de Graduación, Maestria en derechos Humanos. Universidad Estatal a Distancia. Acceso el 14 de marzo de 2016 de http://repositorio.uned.ac.cr/reuned/handle/120809/1313

Muñoz Guillén, Mercedes. 1999. «Narcotráfico, Democracia y Soberanía Nacional en Costa Rica» Anuario de Estudios Centroamericanos, 25(2), 
33-47. Acceso el 25 marzo de 2016 de http://www.redalyc.org/pdf/152/15225202.pdf

Murga Frassinetti, Antonio. 2009. «La participación política de los estudiantes universitarios en el primer gobierno de alternancia en México.» Región y Sociedad, 21(45): 45-63. Acceso el 2 de marzo de 2016 de http://www.redalyc.org/articulo.oa?id=10211819002

Murillo, Luis. 2015. «El Marketing Político Y Sus Consecuencias Para La Democracia» Comunicación Y Sociedad (4): 11-38. Acceso el 28 de marzo de 2016 de http://www.redalyc.org/articulo.oa?id=34600401

Oyarzún Chicuy, Astrid. 2001. «Políticas públicas y mujer joven: entre la madre y la hija» Última Década (14): 75-90. Acces el 16 de marzo de http://www.redalyc.org/articulo.oa?id=19501404

Pac Salas, David y Jaime Minguijón Pablo. 2011. «Percepción ciudadana de la participación sociopolítica». Revista de Investigaciones Políticas y Sociológicas (10) 2. 117-129. Acceso el 5 de febrero de 2016 de http://www.redalyc.org/articulo.oa?id=38021386007

Pastor Seller, Enrique. 2011. «Gobernanza de las políticas de proximidad: análisis de calidad y rendimiento democrático de los Consejos Locales Bienestar (Murcia, España)» Revista de Administração Pública, 45: 377-399. Acceso el 16 de marzo de 2016 de http://www.redalyc.org/articulo.oa?id=241018592005

Pataro Alejandra, Alicia Lenzi y Julieta D’ Avirro. 2008. «Relaciones entre saberes políticos, participación política y educación política. Aportes de la investigación psicológica» Anuario de Investigaciones 15: 125-134. Acceso el 28 de marzo de 2016 de http://www.redalyc.org/articulo.oa? id $=369139944010$

Pérez, Nielsen. 2009. «La Cuota Mínima De Participación Política De Las Mujeres Y Las Minorías Étnicas En Costa Rica: Entre Lo Visible y Lo No Visible» Revista Feminista Casa De La Mujer 0 (15): 31-44. Acceso 
el 15 de marzo de 2016 de

http://revistas.una.ac.cr/index.php/mujer/article/view/6792

Piedra Guillén, Nancy. 2001. «Promotoras de cambios, protagonistas de luchas: cultura política de las mujeres en Costa Rica» Diálogos Revista Electrónica de Historia 2(1): 1-41. Acceso el 28 de maro de 2016 de http://revistas.ucr.ac.cr/index.php/dialogos/article/view/6308

Poggi, Marina y Alejandra Salomón. 2015. «Prensa y Participación Popular En El Ámbito Municipal De La Argentina Peronista». Revista Estudios, 31: 1-28. Acceso el 28 de marzo de 2016 de http://revistas.ucr.ac.cr/index.php/estudios/article/view/22631

Ponce, José Ignacio. 2014. «Adaptación e inclusión de la Izquierda revolucionaria en las transiciones democráticas de Uruguay, Chile y Argentina. Una mirada desde el desempeño electoral, 1983-2009» Revista Izquierdas, (18): 17-36. Acceso el 28 de marzo de 2016 de http://www.redalyc.org/articulo.oa?id=360133466002

Quirós Castro, Rodrigo. 2007. «Las representaciones sociales de la clase media en las coyunturas de conflicto social en la Costa Rica neoliberal. 1984-2000» Diálogos Revista Electrónica de Historia, 8(1): 86-133. Acceso el 28 de marzo de 2016 de http://revistas.ucr.ac.cr/index.php/dialogos/article/view/6164

Ramírez Achoy, Jéssica. 2011. «¿Politizando La Maternidad O Maternalizando La Política? Ciudadanía Y Participación Política De Las Mujeres De Los Barrios Del Sur De San José, 1950-1980» Revista De Historia (63-64): 119-137. Acceso el 28 de marzo de http://revistas.una.ac.cr/index.php/historia/article/view/4585

Ramírez Granados, Mario. 2010. «La garantía del funcionamiento democrático de los partidos políticos costarricenses» Revista de Ciencias Sociales, 5(130): 173-183. Acceso el 28 de marzo de 2016 de http://doi.org/10.15517/rcs.v0i130.4162 
Ramírez Viveros, José Miguel. 2012. «La Política Pública de Participación Ciudadana en el gobierno local: caso Alcobendas, España» Confines de Relaciones Internacionales y Ciencia Política, 8(15): 101-131. Acceso el 28 de marzo de 2016 de http://www.redalyc.org/articulo.oa? id $=63324494004$

Ramos Calderón, José Antonio. 2012. «Inclusión/exclusión: una unidad de la diferencia constitutiva de los sistemas sociales» Revista de Ciencias Sociales de la Universidad Iberoamericana 7: 72-99. Acceso el 13 de marzo de 2016 de http://www.redalyc.org/articulo.oa?id=211026873003

Ramos, Alberto. 2008. «Los límites del referendo sobre el tlc como instrumento de participación política en Costa Rica» Revista De Ciencias Sociales (121) 31-47. Acceso el 16 de marzo de 2016 de http://revistas.ucr.ac.cr/index.php/sociales/article/view/10497/9878.

Ramos, Alberto. 2014. 2014. «El poder, las instituciones y la participación política en la gestión del agua en Costa Rica (1821-2010).» San José, Costa Rica: Editorial Arlekin". Anuario Centro De Investigación y Estudios Políticos 5 (0): 122-131. Acceso el 2 de marzo de 2016 de http://revistas.ucr.ac.cr/index.php/ciep/article/view/20795.

Rodríguez Arce, Carlos y Lucía Ulloa Sáenz. 2012. «Identidad nacional, participación ciudadana y TLC: Una lectura a la luz de spots publicitarios» Reflexiones, 91(1): 67-75. Acceso el 28 de marzo de 2016 de http://www.redalyc.org/articulo.oa?id=72923937005

Rodríguez Colmenares, Isabel y Thaís Gutiérrez Briceño. 2012. «Prerrequisitos generales para la formulación de políticas sociales de inclusión: Caso Venezuela» Revista de Ciencias Sociales 18: 628-640. Acceso el 2 de marzo de 2016 de http://www.redalyc.org/articulo.oa? id $=28025469005$

Rodríguez León, Alfonso. 2003. «Gobernabilidad, innovación y participación ciudadana en salud, columna vertebral de la política en salud» Salud 
en Tabasco, 9 (1): 197-199. Acceso el 28 de marzo de 2016 de http://www.redalyc.org/articulo.oa?id=48709110

Rodríguez, Florisabel y Silvia Castro Méndez. 2003. «Centroamérica Joven: Valores Democráticos En La Generación De La Posguerra» Ensayos Pedagógicos, 2(1): 57-80. Acceso el 15 de marzo de 2016 de http://www.revistas.una.ac.cr/index.php/ensayospedagogicos/article/vie w/4517

Rodríguez, Florisabel y Silvia Castro. 2015. «Centroamérica Joven: Valores Democráticos En La Generación De La Posguerra» Universidad Nacional. 2(1), 57-80. Acceso el 15 de marzo de 2016 de 2016 de http://www.repositorio.una.ac.cr/handle/11056/10097?show=full.

Romero, Carmen. 1986. «Mujer popular y participación» Universidad De Costa Rica. Acceso el 28 de marzo de 2016 de http://www.kerwa.ucr.ac.cr/handle/10669/18447.

Rueda Araya, Daniel. 2013. «Gobernanza y subpolítica en la teoría política crítica de Boaventura De Sousa Santos» Perspectivas Rurales Nueva Época (21): 73-86. Acceso el 5 de marzo de 2016 http://www.revistas.una.ac.cr/index.php/perspectivasrurales/article/view/ 4926/4730

Rueda Laffond, José. 2013. «¿Un pasado que no cesa? Discurso patrimonial y memoria pública comunista en el franquismo y la transición española» Revista de Estudios Sociales, 35(47): 12-24. Acceso el 28 de marzo de 2016 de http://doi.org/10.7440/res47.2013.02

Ruiloba Núñez, Juana María. 2014. «¿Es el gobierno local un nuevo espacio para la participación ciudadana? El punto de vista de los alcaldes. El caso español» Estudios Políticos (44): 55-73. Acceso el 15 de marzo de 2016 de http://www.redalyc.org/articulo.oa?id=16431217004

Ruiz Martínez, Ana. 2015. «La participación ciudadana como criterio de valor en evaluaciones de carácter integral. Una aproximación desde la experiencia de AEVAL» Gestión y Análisis de Políticas Públicas (14): 
acceso el 15 de marzo de 2016 de http://www.redalyc.org/articulo.oa? id=281543007009

Sagot Rodríguez, Montserrat. 2010. «Demandas desde la exclusión: representatividad democrática y cuotas de participación política en Costa rica» Revista de Ciencias Sociales (4): 29-43. Acceso el 15 de marzo de 2016 de http://www.redalyc.org/articulo.oa?id=15321318002

Sánchez Ramos, Miguel Ángel. 2009. «La participación ciudadana en la esfera de lo público» Espacios Públicos 12(25):85-102. Acceso el 28 de marzo de 2016 de http://www.redalyc.org/articulo.oa?id=67611350006

Sandoval, Irma, Hugo González, María, Carrillo; Odalía Calderón y Vilma Pernudi. 2002. La población costarricense del gran área metropolitana frente a sus valoraciones ante la corrupción, la política fiscal y la participación ciudadana. Instituto de Estudios Sociales en Población. Heredia: Universidad Nacional.

Sarabia Ríos, Cecilia. 2014. «Mujeres y participación política en el proceso electoral federal 2012 en Ciudad Juárez» Revista de Ciencias Sociales y Humanidades, 23: 112-139. Acceso el 23 de febrero de 2016 de http://www.redalyc.org/articulo.oa?id=85929886006

Somuano Ventura, Fernanda. 2005. «Más allá del voto: modos de participación política no electoral en México» Foro Internacional 45 (1): 65-88. Acceso el 15 de marzo de 2016 de http://www.redalyc.org/articulo.oa?id=59911175003

Sorribas Patricia y Zeneida Garay Reyna. 2014. «La participación, entre la democracia participativa y la democracia directa. Aportes desde un enfoque psicosocial» Investigación y Análisis Sociopolítico y Psicosocial, 10(2): 39-69. Acceso el 15 de marzo de 2016 de http://www.redalyc.org/articulo.oa?id=72638805003

Soto Calderón, Ronald. 2011. «La Inclusión Educativa: Una Tarea Que Le Compete A Toda Una Sociedad». Actualidades Investigativas En 
Educación, 3(1). Universidad de Costa Rica. Acceso el 2 de marzo de 2016 de doi:10.15517/aie.v3i1.9007

Soto Calderón, Ronald. 2003. «La inclusión educativa: Una tarea que le compete a toda una sociedad» Revista Electrónica Actualidades Investigativas en Educación, 3. Acceso el 23 de febrero de 2016 dehttp://www.redalyc.org/articulo.oa?id=44730104

Souto Kristín, Sandra. 2007. «Juventud, teoría e historia: la formación de un sujeto social y de un objeto de análisis» Historia Actual Online. 13: 171192. Acceso el 10 de marzo de 2017 de http://www.historiaactual.org/Publicaciones/index.php/haol/article/viewFile/208/196

Tabares Ochoa, Catalina. 2013. «Los jóvenes y sus discursos reconfiguradores de la política. Acciones políticas con las que resisten la cultura política tradicional» Estudios Políticos (42): 138-156. Acceso el 28 de marzo de 2016 de http://www.redalyc.org/articulo.oa? $i d=16429070007$

Torres Fragoso, Jaime. 2008. «Marco conceptual de la gerencia pública para América Latina» Cuadernos de Administración (39): 19-28. Acceso el 16 de marzo de 2016 de http://www.redalyc.org/articulo.oa? id $=225020360002$

Vargas Ramos, Carlos.2005. «El género y la participación política en Puerto Rico» Caribbean Studies, 33(1): 205-248. Acceso el 29 de marzo de 2016 de http://www.redalyc.org/pdf/392/39233108.pdf

Vargas, Jean. 2003. «De la representatividad política a la participación ciudadana: el camino hacia la consolidación democrática en Centroamérica» Anuario de Estudios Centroamericanos, 29(1-2): 7-67. Acceso el 26 de marzo de 2016 de http://revistas.ucr.ac.cr/index.php/anuario/article/view/1779

Vásquez, Jorge Daniel. 2017. «Imaginario moderno/colonial y resistencias desde epistemologías y prácticas otras» Instituto De Estudios 
Latinoamericanos. Acceso el 15 de marzo de 2016 de http://www.repositorio.una.ac.cr/handle/11056/6914.

Vega Sanchez, Álvaro. 1997. «El conflicto sociopolítico en 1996: Resumen analítico de coyuntura» Economía y Sociedad, 2(04). Acceso el 15 de marzod e 2016 de http://www.revistas.una.ac.cr/index.php/economia/article/view/1639/155 4

Vega, Mylena. 1992. «Cultura política y legitimidad. Encuesta de opinión entre estudiantes avanzados de la sede central de la Universidad de Costa Rica» Anuario de Estudios Centroamericanos, 18(2): 71-90. Acceso el 28 de marzo del 2016 de http://revistas.ucr.ac.cr/index.php/anuario/article/view/2276/2235

Vindas Solano, Sofía. 2014. «Acción colectiva y ciclos de protesta: experiencias de participación política en La Carpio, 1993-2013» Anuario Centro de Investigación y Estudios Políticos, 3: 91-125. Acceso el 28 de marzo de 2016 de http://revistas.ucr.ac.cr/index.php/ciep/article/view/14643

Viñarás Abad, Mónica. 2013. «Estrategias de comunicación para generar confianza» Comunicación y Hombre: 58-73. Acceso el 28 de febrero de 2016 de http://www.redalyc.org/articulo.oa?id=129429455004

Virriel López, Concepción. 2000.«El problema de la credibilidad de los spots políticos» Revista Mexicana de Ciencias Políticas y Sociales 44 (180): 175-190 acceso el 14 de marzo de 2016 de http://www.redalyc.org/articulo.oa?id=42118014

Zamitiz, Héctor. 1998. Credibilidad, instituciones y vida Pública. México D.F.: Facultad de Ciencias Políticas y Sociales, UNAM.

Zapata Galindo, Martha. 2011. «Conferencia Movilidad E Inclusión Social: Retos Para La Educación Universitaria» Revista Feminista Casa De La Mujer, 15(18-19): 38-55. Acceso el 2 de marzo de 2016 http://www.revistas.una.ac.cr/index.php/mujer/article/view/6810/6972. 
Zúñiga Nuñez, Mario. 2003. Cartografía de los mundos posibles: miradas de protesta a la sociedad desde el rock y reggae costarricense. Informe final del concurso: Movimientos sociales y nuevos conflictos en América Latina y el Caribe. Programa Regional de Becas CLACSO. Acceso el 17 de Mayo de 2017 de: http://biblioteca.clacso.edu.ar/clacso/becas/20110127084829/zuniga.pd f 